\title{
Two bicistronic DNA vaccines against Vibrio anguillarum and the immune effects on flounder Paralichthys olivaceus*
}

\author{
Hanlin $\mathrm{LI}^{1}$, Jing XING ${ }^{1,2, * *}$, Xiaoqian TANG ${ }^{1,2}$, Xiuzhen SHENG ${ }^{1}$, Heng CHI ${ }^{1}$, Wenbin ZHAN ${ }^{1,2}$ \\ ${ }^{1}$ Laboratory of Pathology and Immunology of Aquatic Animals, KLMME, Ocean University of China, Qingdao 266003, China \\ ${ }^{2}$ Laboratory for Marine Fisheries Science and Food Production Processes, Pilot National Laboratory for Marine Science and \\ Technology (Qingdao), Qingdao 266071, China
}

Received Mar. 22, 2021; accepted in principle Apr. 22, 2021; accepted for publication May 11, 2021

(C) Chinese Society for Oceanology and Limnology, Science Press and Springer-Verlag GmbH Germany, part of Springer Nature 2022

\begin{abstract}
Chemokines are cytokines that can promote the activation and migration of immune cells, and increase the recognition of antigen by antigen-presenting cells (APC). Previous studies showed that a DNA vaccine can induce humoral and cellular immune responses of flounder after immunization. To explore the improvement of chemokines on the efficiency of OmpK vaccine, two bicistronic DNA candidate vaccines were constructed and the immune responses they induced in the flounder were investigated by reverse transcription polymerase chain reaction (RT-PCR), indirect immunofluorescent assay (IFA), H\&E staining, flow cytometry (FCM), and quantificational real-time polymerase chain reaction (qRT-PCR). pBudCE4.1 plasmid as an expression vector, bicistronic DNA vaccines encoding OmpK gene and CC-motif ligand 4 gene (p-OmpKCCL4), or Ompk gene and CC-motif ligand 19 gene (p-OmpK-CCL19) were successfully constructed. The results showed that two bicistronic DNA vaccines expressed Ompk protein of Vibrio anguillarum and CCL4/ CCL19 proteins of flounder both in vitro and in vivo. After immunization, a large number of leucocytes in muscle were recruited at the injection site in treatment groups. The constructed vaccines induced significant increases in CD4- $1^{+}$and CD4-2+ $\mathrm{T}$ lymphocytes, and $\operatorname{sgM} \mathrm{M}^{+} \mathrm{B}$ lymphocytes in peripheral blood, spleen, and head kidney. The percentage of $\mathrm{T}$ lymphocytes peaked on the $14^{\text {th }}$ post-vaccination day whereas that of $\mathrm{B}$ lymphocytes peaked in the $6^{\text {th }}$ post-vaccination week. Moreover, the expression profiles of 10 immune-related genes increased in muscles around the injection site, spleen, and head kidney. After the challenge, p-OmpKCCL4 and p-OmpK-CCL19 conferred a relative percentage survival (RPS) of $74.1 \%$ and $63.3 \%$, respectively, higher than p-OmpK alone (40.8\%). In conclusion, both CCL4 and CCL19 can improve the protection of p-OmpK via evoking local immune response and then humoral and cellular immunity. CCL4 and CCL19 will be potential molecular adjuvants for use in DNA vaccines.
\end{abstract}

Keyword: Vibrio anguillarum; outer membrane protein K; bicistronic DNA vaccines; CC-motif ligand 4; CC-motif ligand 19; immune response

\section{INTRODUCTION}

DNA vaccines can provide good protection after immunization because its ability to induce humoral and cellular immune responses, therefore, it has been proven to be a very promising strategy in disease prevention, especially against viral diseases (Cui, 2005; Chang, 2020). Using adjuvants is one of the most effective ways to increase the effectiveness of DNA vaccines, including IL-2, IL-6, IFN- $\gamma$, TNF- $\alpha$, and other cytokines (Lu et al., 2008; Su et al., 2008; Gaertner et al., 2009; Tang et al., 2020).

Vibrio anguillarum is a gram-negative pathogen in aquaculture, which threatens aquatic animals

\footnotetext{
* Supported by the National Natural Science Foundation of China (Nos. 32173005, 31730101, 31672684), the National Key Research and Development Program of China (No. 2018YFD0900503), the Shandong Provincial Natural Science Foundation (No. ZR2020KC025), the Fundamental Research Funds for the Central Universities (No. 201822015), the Director Foundation of Functional Laboratory for Marine Fisheries Science and Food Production Processes, Qingdao National Laboratory for Marine Science and Technology (No. 2018MFSD-01), the NBRPC (No. 2012CB114406), the Key Research and Development Program of Shandong Province (No. 2016GNC115001), and the Taishan Scholar Program of Shandong Province

** Corresponding author: xingjing@ouc.edu.cn
} 
seriously. A large number of studies on the vaccine against $V$. anguillarum have been performed to prevent fish disease caused by $V$. anguillarum. Inactivated vaccines, live attenuated vaccines, subunit vaccines, and DNA vaccines against $V$. anguillarum were reported previously (Hamod et al., 2012; Xing et al., 2018; Xu et al., 2019a, b, c; Li et al., 2020). The advantages of the DNA vaccines include its versatility, safety, ease of production, and low cost compared to traditional vaccines (Klinman et al., 2010). In a previous study, a DNA vaccine encoding the OmpK gene of $V$. anguillarum was constructed successfully, it can induce humoral and cellular immune responses in flounder by intramuscular injection (Xu et al., 2019a).

Chemokines are inflammatory molecules with high biological activity, and they can bind to specific receptors and play an important role in the immune response, such as activating different types of lymphocytes and inducing the migration of lymphocytes to inflammatory foic (Kim et al., 2000). Inflammatory chemokines are thought to recruit neutrophils, monocytes/macrophages, dendritic cells (DC), and natural killer cells (NK). Therefore, they play an important role in mediating a variety of immune and inflammatory responses (Esche et al., 2005). According to the number and position of the first two cysteine residues in their sequence, chemokines can be classified into four subfamilies, including CXC, CC, CX3C, and XC (Zou et al., 2014). Chemokines bind to their receptors causes the recruitment and activation of intracellular G-proteins that initiate a variety of signaling pathways (Bonecchi and Graham, 2016). They can chemotactic on monocytes/macrophages, T cells, B cells, eosinophils, dendritic cells, mast cells, natural killer cells, etc., and participate in the inflammatory response and the pathogenesis of various diseases (Kono et al., 2003). Chemokine CC-motif ligand 4 (CCL4) and chemokine CC-motif ligand 19 (CCL19) are members of the CCchemokine subfamily, and their specific receptors are chemokine receptor 5 (CCR5) and chemokine receptor 7 (CCR7), respectively (Bonecchi et al., 2009). CCL4 is also known as macrophage inflammatory protein- $1 \beta$ (MIP-1 $\beta$ ) and it is a member of the inflammatory chemokine family, which binds to its specific receptor CCR5 and acts on a variety of immune effector cells, including NK, T cells, DC, and monocytes (Alejo and Tafalla, 2011; Li et al., 2011). CCL19, also known as

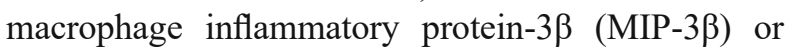
EBI1 ligand chemokine (ELC), which binds to its specific receptor CCR7 and induces DC maturation and increases DC co-stimulatory molecules and proinflammatory cells factor production to promote $\mathrm{T}$ cell proliferation (Kutzler and Weiner, 2004; Maurer and von Stebut, 2004). Many kinds of research on chemokines as vaccine adjuvants have been performed in mammals and fish (Yamano et al., 2006; Kutzler et al., 2010; Matsuo et al., 2018; Choi et al., 2019; Kamei et al., 2020).

In this study, CCL4 and CCL19 were coupled into OmpK-based DNA vaccine, respectively. Two bicistronic DNA vaccines were constructed. The transcription and expression of these bicistronic DNA vaccines were verified in vivo and in vitro. Then immune responses they induced in flounder after immunization were investigated. The purpose of this paper is to explore the adjuvant potential of CCL4 and CCL19 on the OmpK-based DNA vaccine against $V$. anguillarum.

\section{MATERIAL AND METHOD}

\subsection{Fish}

Flounder (Paralichthys olivaceus, $35 \pm 5 \mathrm{~g}$ ) were obtained from a fish farm (Rizhao, Shandong, China), and all of the fish were held in the wet lab at $21 \pm 0.5^{\circ} \mathrm{C}$ for two weeks before the experiments for acclimatization and evaluation of overall fish health. Fish was randomly sampled before the experiment. General appearance, level of activity, bacteria isolation, and molecular biological detection (PCR) were performed to confirm $V$. anguillarum free. Then only healthy fish were used in the following experiments. Anesthetized the fish with tricaine methanesulfonate (MS222, Sigma, USA), and the subsequent operation was performed. All efforts were dedicated to minimizing suffering.

Investigations were performed strictly according to the ethical standards and the Guidelines of "Regulations for the Administration of Affairs Concerning Experimental Animals" documented by the State Science and Technology Commission of Shandong Province. These studies were also approved by the Committee of the Ethics on Animal Care and Experiments in Ocean University of China.

\subsection{Bacteria, plasmids, antibodies, and cells}

The pathogenic $V$. anguillarum SJ060621 was stored in our lab (Tang et al., 2008). The strain was cultured in 2216E marine medium at $28{ }^{\circ} \mathrm{C}$ for $24 \mathrm{~h}$ and diluted with phosphate buffered solution (PBS) to 
Table 1 The primers used in this study

\begin{tabular}{|c|c|c|}
\hline Primer name & Primer sequence $\left(5^{\prime} \rightarrow 3^{\prime}\right)$ & Source \\
\hline CCL4-F & CCCAAGCTTATGGCTGCTGCTCGTCTATGTCT & \multirow{2}{*}{ AB937786.1 } \\
\hline CCL4-R & CGGGATCCTTACAGGTTGGACGCCTCTCCTGGC & \\
\hline CCL19-F & CCCAAGCTTATGGCTCCGAGGGGTGAT & \multirow{2}{*}{ AB937788.1 } \\
\hline CCL19-R & CGGGATCCAACACTTCCCTTGGCC & \\
\hline OmpK-F & GGGGTACCACCATGGCTGACTATTCAGATGGCG & \multirow{2}{*}{ FJ705222.1 } \\
\hline OmpK-R & CCGCTCGAGTTAGAACTTGTAAGTCACAGC & \\
\hline 18sRNA-F & GGTCTGTGATGCCCTTAGATGTC & \multirow{2}{*}{ EF126037 } \\
\hline 18sRNA-R & AGTGGGGTTCAGCGGGTTAC & \\
\hline IgM-F & AAGTCCACAAATTACCCTCCAA & \multirow{2}{*}{ AB052744 } \\
\hline $\operatorname{IgM}-\mathrm{R}$ & TTCTCGCTTTTATGTTCCTCAG & \\
\hline MHCI $\alpha-F$ & AGACCACAGGCTGTTATCACCA & \multirow{2}{*}{ AB126921 } \\
\hline MHCI $\alpha-\mathrm{R}$ & TCTTCCCATGCTCCACGAA & \\
\hline MHCII $\alpha-F$ & ACAGGGACGGAACTTATCAACG & \multirow{2}{*}{ AY99753 } \\
\hline MHCII $\alpha-\mathrm{R}$ & TCATCGGACTGGAGGGAGG & \\
\hline CD4-1-F & CCAGTGGTCCCCACCTAAAA & \multirow{2}{*}{ AB643634 } \\
\hline CD4-1-R & CACTTCTGGGACGGTGAGATG & \\
\hline CD4-2-F & CACAGCGAGGACGTCAGAAA & \multirow{2}{*}{ AB640684 } \\
\hline CD4-2-R & TCTCTCCCATCACTCCTTTAGCA & \\
\hline $\mathrm{CD} 8 \beta-\mathrm{F}$ & GATGACACTCAAACCTCCAGTCAA & \multirow{2}{*}{ AB643633 } \\
\hline $\mathrm{CD} 8 \beta-\mathrm{R}$ & GCCATCCTGTGCAAAATTCTTC & \\
\hline IL2-F & AGAGGATGCCAGTATCGGTTT & \multirow{2}{*}{ KY307833 } \\
\hline IL2-R & CAACGACCTCCGCAGAATGT & \\
\hline IL6_F & CTCCGCAATGGGAAGGTG & \multirow{2}{*}{ DQ267937 } \\
\hline IL6_R & AGTGGATGGGTGGAATAA & \\
\hline IFN- $\gamma-\mathrm{F}$ & TGTCAGGTCAGAGGATCACACAT & \multirow{2}{*}{ AB435093 } \\
\hline IFN- $\gamma-\mathrm{R}$ & GCAGGAGGTTCTGGATGGTTT & \\
\hline CD83-F & CCCAACGGCACGACGACATAC & \multirow{2}{*}{ KR998303.1 } \\
\hline CD83-R & CCCAAAGGTGCTGCCAGGTGA & \\
\hline GATA-3-F & CAGGAGGACAAAGAGTGCATAAAGT & \multirow{2}{*}{ XM_020108979.1 } \\
\hline GATA-3-R & GAAGATGACCCACCTATCAGGCTAC & \\
\hline
\end{tabular}

the final concentration of $1.0 \times 10^{8} \mathrm{CFU} / \mathrm{mL}$ for challenge.

The eukaryotic plasmid pBudCE4.1 (Invitrogen, Carlsbad, CA, USA) contains two multiple cloning sites, which are located downstream of the human cytomegalovirus (CMV) immediate-early promoter and the human elongation factor $1 \alpha$ subunit (EF-1 $\alpha$ ) promoter. There is $6 \times$ His-tag on the downstream of multiple cloning sites in pBudCE4.1, and the terminator is downstream of the $6 \times$ His-tag. Specific primers without terminator were designed for amplification of CCL4 and CCL19 genes (Table 1) to enable the recombinant plasmids to express CCL4/ CCL19 with $6 \times$ His-tag. Therefore, the expression of CCL4 and CCL19 proteins can be detected by mouse- anti His-tag monoclonal antibodies, and the expression of OmpK protein can be detected by rabbit-anti OmpK polyclonal antibodies.

Recombinant OmpK protein with GST tag (rOmpKGST) was expressed and purified in Escherichia coli, and used for the preparation of rabbit anti-rOmpK polyclonal antibody according to previous reports (Ahmadivand et al., 2018; Jung et al., 2018). Western blot was used to detect the specificity of the polyclonal antibodies, and it was found that the antiserum could specifically bind to purified rOmpK-GST and OmpK protein from $V$. anguillarum (Supplementary Material). Mouse-anti His-tag monoclonal antibodies were purchased from Biyuntian, China. Mouse anti- 


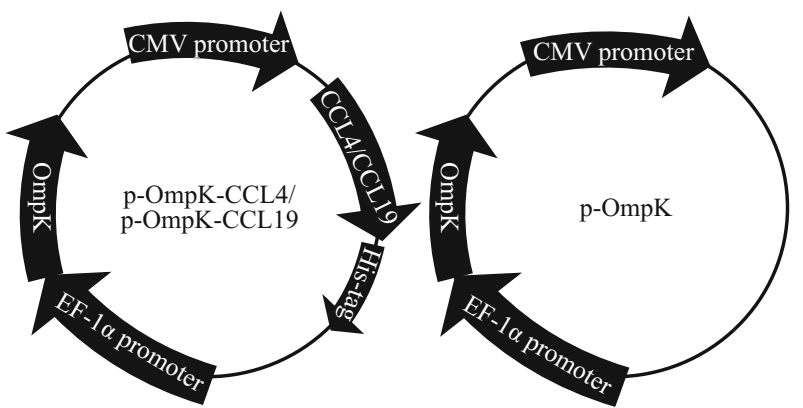

Fig.1 The diagram of p-OmpK-CCL4/p-OmpK-CCL19 and p-OmpK

flounder IgM monoclonal antibodies (FIgM-Mab) and mouse anti-flounder CD4-1, CD4-2 monoclonal antibodies (FCD4-1-Pab, FCD4-2-Pab) were produced previously in our laboratory (Li et al., 2007; Tian et al., 2019). In this study, mouse-anti His-tag monoclonal antibodies and rabbit-anti rOmpK-GST polyclonal antibodies were diluted into 1:200 and 1:1000 respectively with PBS for indirect immunofluorescent assay (IFA). The ascites fluids of FIgM-Mab, FCD41-Pab, and FCD4-2-Pab were diluted into 1:1000 and were used in flow cytometry (FCM).

Hirame natural embryo (HINAE) cells were kindly provided by Dr. Ikuo Hirono, the professor of Tokyo University of Marine Science and Technology and stored in our lab (Liu et al., 2016b). The cells were plated in 6-well plates, cultured with Leibovitz's L-15 medium (Thermo Fisher, MA, USA) containing 20\% fetal calf serum (FBS), 100-IU/mL penicillin, and $100-\mu \mathrm{g} / \mathrm{mL}$ streptomycin, and used for transfection to analyze the expression of OmpK and CCL4/CCL19 proteins.

\subsection{Plasmids construction and preparation}

The pathogenic $V$. anguillarum SJ060621 was cultured in $2216 \mathrm{E}$ marine medium at $28^{\circ} \mathrm{C}$ for $8 \mathrm{~h}$, and the bacteria suspensions were used as the template for amplification of OmpK gene with specific primers (Table 1). According to the instructions, the PCR products were purified using TIANgel Midi Purification Kit (Tiangen, China) and digested with $\mathrm{KpnI}$ and XhoI, and then the digested PCR products were inserted into the multiple cloning sites under the control of the EF- $1 \alpha$ promoter in pBudCE4.1 to construct the $\mathrm{p}-\mathrm{OmpK}$ plasmid. According to the manufacturer's instructions, total RNA from spleen of the flounder was extracted using TRIZOL reagent (Bao Sheng, Dalian, China) and measured the concentration by Nanodrop 8000 spectrophotometer (Thermo Fisher, MA, USA). The first strand of complementary DNA (cDNA) was synthesized by the reverse transcriptase M-MLV kit (TaKaRa, Dalian, China). Refer to the sequences from NCBI (Gene bank accession Nos. AB937786.1 and AB937788.1), the CCL4 and CCL19 genes of flounder were amplified using the designed specific primers, respectively (Table 1). The PCR products of CCL4 and CCL9 were digested with HindIII and BamHI, and then were inserted multiple cloning sites on the downstream of CMV promoter of $\mathrm{p}-\mathrm{OmpK}$ plasmid respectively to construct p-OmpK-CCL4 and $\mathrm{p}$-OmpK-CCL19. The diagram of $\mathrm{p}-\mathrm{OmpK}-\mathrm{CCL} 4 \mathrm{p}-$ OmpK-CCL19 and p-OmpK is shown in Fig.1.

To prove the accuracy of the transgene, these recombinant plasmids ( $\mathrm{p}-\mathrm{OmpK}$, $\mathrm{p}-\mathrm{OmpK}-\mathrm{CCL} 4$, and p-OmpK-CCL19) were subjected to DNA sequencing (Tsingke, Qingdao, China), moreover, they were determined by double digestion to detect the foreign genes that have been successfully inserted into pBudCE4.1 plasmid. According to the manufacturer's instructions, endotoxin-free recombinant plasmids were purified using Endo Free Plasmid Kit (Tiangen, China), and the concentration was quantified using Nanodrop 8000 spectrophotometer. These plasmids are used for subsequent transfection and injection.

\subsection{Expression of plasmids in vitro}

According to the manufacturer's instructions of Lipofectamine $^{\circledR} 3000$ (Thermo Fisher, MA, USA), approximately $70 \%-80 \%$ confluent HINAE cells were transfected with 500-ng p-OmpK-CCL4, p-OmpK-CCL19, p-OmpK, and pBudCE4.1, respectively. The cells were cultured at $24^{\circ} \mathrm{C}$ for $48 \mathrm{~h}$ and then digested with pancreatin and resuspended with PBS. After that, the cells were dropped on adherent glass slides, left at room temperature for $2 \mathrm{~h}$, and then fixed with $4 \%(\mathrm{w} / \mathrm{v})$ paraformaldehyde for $15 \mathrm{~min}$ for IFA. Briefly, transfected cells were inoculated with rabbit-anti rOmpK-GST polyclonal antibody (1:1 000) and mouse-anti His-tag monoclonal antibody (1:200, Biyuntian, China) for $1 \mathrm{~h}$ at $37^{\circ} \mathrm{C}$, and then goat-anti-rabbit Ig-Alexa Fluor ${ }^{\circledR} 649$ and goat-anti-mouse Ig-Alexa Fluor ${ }^{\circledR} 488$ (1:1 000, Thermo Fisher Scientific, USA) were inoculated with the transfected cells for $45 \mathrm{~min}$ at $37^{\circ} \mathrm{C}$. Finally, cells were stained with nuclei of 4', 6-diamidino-2phenylindole (DAPI, 1:1 000, Invitrogen, Carlsbad, USA) for $15 \mathrm{~min}$ at room temperature, and then specific fluorescence was imaged by epi-fluorescence microscope IX71 (Olympus, Japan). The observation 
field was randomly selected and the number of cells with fluorescence per 100 cells was counted in p-OmpK-CCL4, p-OmpK-CCL19, and p-OmpK groups. This operation was repeated five times. Cells transfected with pBudCE4.1 plasmid served as a negative control.

\subsection{Transcription and expression of plasmids in vivo}

RT-PCR and IFA were performed to analyze the transcription and expression of p-OmpK-CCL4, p-OmpK-CCL19, and p-OmpK in muscles on the $3^{\text {th }}$ day after immunization. Total RNA was exacted by TRIZOL reagent (Bao Sheng, Dalian, China) and cDNA was generated by Reverse Transcriptase M-MLV kit (TaKaRa), the template of PCR amplification was the cDNA. The specific primers of the study are shown in Table 1.

Muscle tissue cryosections were prepared according to the method previously (Wu et al, 2009). The frozen sections of muscle were washed with PBST (PBS containing $0.05 \%$ Tween 20) for $5 \mathrm{~min}$ and blocked with $5 \%$ bovine serum albumin (BSA) in PBS for $1 \mathrm{~h}$ at $37^{\circ} \mathrm{C}$, then these sections incubate with rabbit-anti rOmpK-GST polyclonal antibodies $(1: 1000)$ and mouse-anti His-Tag monoclonal antibodies $(1: 200)$ for $1 \mathrm{~h}$ at $37^{\circ} \mathrm{C}$, goat-anti-rabbit Ig-Alexa Fluor ${ }^{\circledR} 649(1: 1000)$ and goat-anti-mouse Ig-Alexa Fluor ${ }^{\circledR} 488(1: 1000)$ as secondary antibodies for $45 \mathrm{~min}$ at $37^{\circ} \mathrm{C}$ and then stained with DAPI in a moisture chamber for $15 \mathrm{~min}$ at room temperature. Finally, these sections were washed three times by PBST and mounted in buffered glycerin for observation with fluorescence microscopy IX71 (Olympus, Japan). Wash three times with PBST after each step. The frozen sections from pBudCE4.1 group were used as the negative control.

\subsection{Fish vaccination and sampling}

Healthy individuals were divided into 4 groups (120 fish per group), and the 120 fish were evenly divided into 5 tanks. Fish were sampled randomly and RT-PCR was conducted to detect the level of CCL4 and CCL19 in healthy flounder, and the results showed that the level of CCL4 and CCL19 in healthy flounder was no significant difference compared with the flounder injected with pBudCE4.1 (data not shown). The fish were injected with $20 \mu \mathrm{g}$ of pBudCE4.1, p-OmpK, p-OmpK-CCL4, and p-OmpKCCL19, respectively (100 $\mu \mathrm{L}$ per individual). After injection, samples were randomly taken from each group to detect the immune response of the flounder.
The percentage of $\mathrm{CD} 4-1^{+}$and $\mathrm{CD} 4-2^{+} \mathrm{T}$ lymphocytes was detected by FCM after immunization. Three individuals were randomly selected in each group, and then the peripheral blood (PBL), spleen, and head kidney were sampled on the $3^{\text {rd }}, 5^{\text {th }}, 7^{\text {th }}, 14^{\text {th }}, 21^{\text {st }}$, and $28^{\text {th }}$ day, respectively. The isolation protocol of lymphocytes of PBL, spleen, and head kidney was performed according to a previously reported method ( $\mathrm{Li}$ et al., 2007). Then, the isolated lymphocytes were adjusted to $1.0 \times 10^{7}$ cells $/ \mathrm{mL}$, and were used to analyze the percentage of CD4- $1^{+}$and CD4-2 $2^{+}$T lymphocytes. Similarly, three individuals were randomly selected in each group after immunization, and then the PBL, spleen, and head kidney were sampled in the $1^{\text {st }}, 2^{\text {nd }}, 3^{\text {rd }}, 4^{\text {th }}, 5^{\text {th }}, 6^{\text {th }}$, and $7^{\text {th }}$ week, respectively. The lymphocytes were collected as described above and then were used to analyze the percentage of $\operatorname{sig} \mathrm{M}^{+} \mathrm{B}$ lymphocytes.

The injection sites were collected from three individuals in each group on the $5^{\text {th }}$ day after immunization for detecting the recruitment of leucocytes by $H \& E$ staining.

The muscles, spleen, and head kidney were dissected from three individuals from each group on the $7^{\text {th }}$ day after immunization and stored in RNA Later reagent (TaKaRa), were used to detect the expression profiles of immune-related genes by qRTPCR.

\subsection{H\&E staining}

The muscles at the injection site were fixed with Bonn's fluid for $20 \mathrm{~h}$, and all samples were dehydrated and embedded in paraffin wax after rinsed with $75 \%$ alcohol, then $7-\mu \mathrm{m}$ sections were cut using a rotary microtome (Leica, Heidelberg, Germany) and mounted on pretreated slides. After deparaffinized with xylene and $50 \%$ xylene/ethanol solution, these sections were rehydrated by successive immersion in $95 \%, 80 \%, 70 \%, 50 \%$, and $30 \%$ ethanol for $5 \mathrm{~min}$ each step. These sections were stained with hematoxylin for $20 \mathrm{~min}$, and after differentiated in $1 \%$ acidic alcohol for $30 \mathrm{~s}$, the sections were washed with water for $30 \mathrm{~min}$. Next, after stained with eosin for $10 \mathrm{~s}$ and differentiated in $95 \%$ ethanol for $30 \mathrm{~s}$, the sections were dehydrated through a series of ethanol solutions $(30 \%, 50 \%, 70 \%, 80 \%$, and 95\%). Finally, the sections were dehydrated in $100 \%$ ethanol and cleared in xylene. Subsequently, they were fixed with neutral balsam and examined for histological changes by a light microscope (Olympus DP70, Japan). 


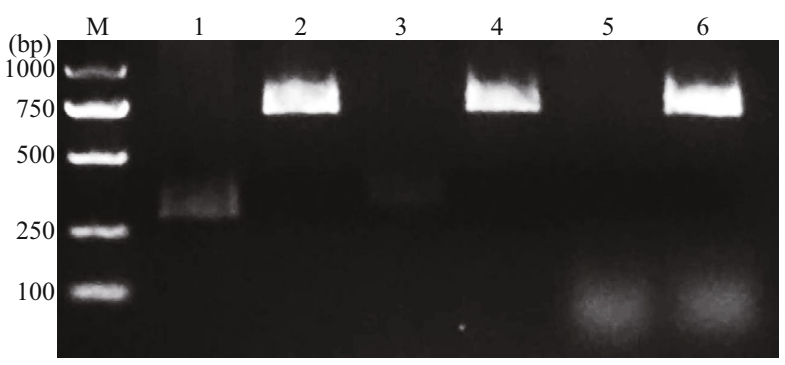

Fig.2 Digestion of recombinant plasmids

Lane M: marker; lanes 1, 3, and 5: p-OmpK-CCL4, p-OmpK-CCL19, and p-OmpK plasmids digested by BamHI and HindIII, respectively; lanes 2, 4, and 6: p-OmpK-CCL4, p-OmpK-CCL19, and p-OmpK plasmids digested by XhoI and KpnI, respectively.

\subsection{Flow cytometry}

For CD4- $1^{+}$and CD4-2+ $\mathrm{T}$ lymphocytes detection after immunization, the lymphocytes were incubated with FCD4-1-Pab or FCD4-2-Pab for $1 \mathrm{~h}$ at $37^{\circ} \mathrm{C}$, after washing with PBS for three times, incubated goat-anti-mouse Ig-Alexa Fluor ${ }^{\circledR} 488$ (1:1 000, Thermo Fisher Scientific, USA) for $1 \mathrm{~h}$ in the dark at $37^{\circ} \mathrm{C}$, and then the lymphocytes were washed three times with $\mathrm{PBS}$ and the cell suspensions were analyzed by Accuri C6 cytometer (BD Accuri., USA). For detecting $\operatorname{sIgM}^{+}$B lymphocytes after vaccination, the lymphocytes were incubated with FIgM-Mab for $1 \mathrm{~h}$ at $37^{\circ} \mathrm{C}$, and then incubated goat-anti-mouse IgAlexa Fluor ${ }^{\circledR} 649$ (1:1 000, Thermo Fisher Scientific, USA) for $1 \mathrm{~h}$ in the dark at $37^{\circ} \mathrm{C}$ after washing by PBS for three times. And then the cell suspensions were analyzed by Accuri C6 cytometer. Fluorescent light (FL)-1 and FL-4 were used to determine Alexa Fluor $^{\circledR} 488$ labeled cells and Alexa Fluor ${ }^{\circledR} 649$ labeled cells, respectively. The myeloma culture supernatant instead of FIgM-Mab, and mouse negative serum instead of FCD4-1-Pab or FCD4-2-Pab were used as negative controls.

\section{9 qRT-PCR}

The immune response of $\mathrm{T}, \mathrm{B}$ lymphocytes in flounder was significantly enhanced on the $7^{\text {th }}$ day after immunization with DNA vaccines based on our previous researches (Liu et al., 2017b; Xu et al., 2019a), therefore, the expression of genes related to $\mathrm{T}$, B lymphocytes immune response was detected (IgM, MHC I, MHC II, CD8 $\beta$, CD4-1, CD4-2, IFN- $\gamma$, IL-2, IL-6, CD83, and GATA-3). Three individuals were randomly killed from each group on the $7^{\text {th }}$ day after immunization, total RNA was extracted from muscles, spleen, and head kidney, and then cDNA was generated by Reverse Transcriptase M-MLV kit (TaKaRa) following the manufacturer's instructions.
qRT-PCR was performed by SYBR Green I Master Mix (Roche, Basel, Switzerland) in Light Cycle ${ }^{\circledR}$ 48II Real-Time PCR System (Roche, Basel, Switzerland). The specific primers are shown in Table 1. The thermal cycling profile consisted of an initial denaturation at $95{ }^{\circ} \mathrm{C}$ for $30 \mathrm{~s}$, followed by 45 cycles of denaturation at $95^{\circ} \mathrm{C}$ for $5 \mathrm{~s}$, and extension at $60{ }^{\circ} \mathrm{C}$ for $30 \mathrm{~s}$. An additional temperature ramping step was utilized to produce melting curves of the reaction from $65^{\circ} \mathrm{C}$ to $95^{\circ} \mathrm{C}$. The expression profiles in blank control individuals were defined as 1. Each assay was performed in triplicate and the $18 \mathrm{~S}$ gene as an internal control. All data were analyzed using the $2^{-\Delta \Delta C t}$ method according to a previous report (Livak and Schmittgen, 2001).

\subsection{Challenge}

Seven weeks after vaccination, 30 individuals were randomly selected from each group and injected with $1.0 \times 10^{7} \mathrm{CFU}(10 \times \mathrm{LD} 50)$ live virulent $V$. anguillarum . The fish were also maintained in the oxygen-supplying laboratory water system and the water temperature was $21 \pm 0.5{ }^{\circ} \mathrm{C}$. Mortality was monitored over for $14 \mathrm{~d}$ after challenge, and the relative percentage survival (RPS) was calculated as described previously after determining that the death of flounder was caused by $V$. anguillarum (Amend, 1981).

\subsection{Statistical analysis}

Statistical analysis was performed using GraphPad Prism 5 (GraphPad Software, Inc. San Diego, CA, USA). The differences were determined using a oneway analysis of variance (ANOVA). In all cases, the results were expressed as means $\pm \mathrm{SD}$ (standard deviation), and the significance level was defined as $P<0.05$.

\section{RESULT}

\subsection{Identification of constructed bicistronic DNA vaccines}

As shown in Fig.2, the OmpK, CCL4, and CCL19 genes were successfully inserted into the pBudCE4.1 under the control of EF-1 $\alpha$ promoter and CMV promoter, respectively.

After double digestion, the results of $\mathrm{p}-\mathrm{OmpK}$ CCL4 and p-OmpK-CCL19 (HindIII/BamHI, KpnI/ XhoI) showed that the specific CCL4 and CCL19 bands were observed in lane 1 and 3, and OmpK bands were observed in lane 2 and 4. For p-OmpK plasmid, after digestion with KpnI and XhoI and agarose gel 
electrophoresis, a specific OmpK gene band was observed in lane 6, however, there is no specific gene band after digested by HindIII and BamHI. Moreover, the results of sequencing show that the foreign genes inserted into the plasmid are correct (data not shown). The above results showed that the CCL4, CCL19, and OmpK genes were inserted into the expected sites, and p-OmpK-CCL4 and p-OmpK-CCL19 plasmids were prepared successfully.

\subsection{Expression of bicistronic DNA vaccines in vitro}

The results of IFA showed that HINAE transfected with p-OmpK-CCL4 and p-OmpK-CCL19 plasmids can express OmpK, CCL4, and CCL19 proteins, and HINAE transfected with p-OmpK can only express OmpK protein, but fluorescence was not observed in the pBudCE4.1 group (Fig.3a). Green fluorescence represented CCL4 and CCL19 proteins, and red fluorescence represented OmpK protein. Moreover, the efficiency of transfection in p-OmpK-CCL4, p-OmpK-CCL19, and p-OmpK groups was $12.4 \% \pm 2.28 \%, 10.6 \% \pm 2.68 \%$, and $10.6 \% \pm 2.43 \%$, respectively. However, for the pBudCE4.1 group, there were almost no fluorescent cells (Fig.3b).

\subsection{Transcription and expression of bicistronic DNA vaccines in vivo}

In Fig.4, bright and clear DNA bands are observed in lanes $1,3,5$, and 6, representing CCL4, OmpK, CCL19, and OmpK genes, respectively, which proved that p-OmpK-CCL4 and p-OmpK-CCL19 can be transcribed in the muscles of flounder. Similarly, a bright DNA band of OmpK was observed in lane 9, demonstrating that $\mathrm{p}-\mathrm{OmpK}$ can be transcribed in flounder muscles, but not in the pBudCE4.1-injected fish. Notably, the specific CCL4 gene bands were shown in lanes 2, 7, and 10, and the specific CCL19 gen bands were shown in lanes 4,8 , and 11 , but they were not as clear and bright as those in the p-OmpKCCL4 and p-OmpK-CCL19 groups. This probably because the muscles contain a small amount of CCL4 and CCL19 genes rather than transcribed by recombinant plasmids.

The IFA results showed that the specific green and red fluorescence can be observed in muscles of p-OmpK-CCL4- and p-OmpK-CCL19-injected fish, which revealed that OmpK, CCL4, and CCL19 proteins can be expressed in flounder. In the $\mathrm{p}-\mathrm{OmpK}$ group, only red fluorescence was observed, indicating that the recombinant plasmid can only express OmpK protein in flounder. And there is no specific fluorescence was detected in muscles of the flounder from pBudCE4.1 group (Fig.5).

\subsection{Increase of leukocytes at injection site}

$H \& E$ staining was performed to investigate the recruitment of leukocytes after immunization. The results of H\&E staining showed that a large number of leukocytes were recruited at the injection site of flounder in p-OmpK-CCL4 and p-OmpK-CCL19 groups, followed by the pBudCE4.1-OmpK (p-OmpK) group. But the result of the pBudCE4.1 group showed that little leukocytes were recruited to the injection site (Fig.6).

\subsection{Variations on $T$ lymphocytes in peripheral blood, spleen, and head kidney after immunization}

The percentage of $\mathrm{CD}^{-}-^{+}$and $\mathrm{CD} 4-2^{+} \mathrm{T}$ lymphocytes in PBL, spleen, and head kidney for all groups was showed in Fig.7.

In the control group, $\mathrm{CD} 4-1^{+}$and $\mathrm{CD} 4-2^{+} \mathrm{T}$ lymphocytes maintained relative invariant during the experimental period. In $\mathrm{p}-\mathrm{OmpK}$, $\mathrm{p}-\mathrm{OmpK}-\mathrm{CCL} 4$, and p-OmpK-CCL19 groups, CD4-1 ${ }^{+}$and CD4-2 $2^{+} \mathrm{T}$ lymphocytes increased significantly on the $7^{\text {th }}$ day $(P<0.05)$, and their peak levels occurred on the $14^{\text {th }}$ day, then they reduced slowly. In PBL, spleen, and head kidney, the percentage of CD4-1+ $\mathrm{T}$ lymphocytes were $10.5 \% \pm 0.64 \%$ and $9.4 \% \pm 0.29 \%, 11.9 \% \pm 0.71 \%$ and $9.4 \% \pm 0.74 \%, 19.2 \% \pm 0.50 \%$ and $19.6 \% \pm 0.88 \%$ on the $7^{\text {th }}$ day after immunization, respectively. And the percentage of $\mathrm{CD} 4-2^{+} \mathrm{T}$ lymphocytes were $11 \% \pm 0.67 \%$ and $11.1 \% \pm 0.68 \%, 10.8 \% \pm 0.55 \%$ and $9.8 \% \pm 0.58 \%, \quad 23.1 \% \pm 0.32 \%$, and $23.8 \% \pm 0.68 \%$, respectively. Moreover, it was higher in both p-OmpK-CCL4 and p-OmpK-CCL19 groups than those in the $\mathrm{p}$-OmpK group $(P<0.05)$.

The above results indicated that CCL4 and CCL19 can further increase the percentage of $\mathrm{CD} 4-1^{+}$and CD4-2 $2^{+} \mathrm{T}$ lymphocytes based on the OmpK DNA vaccine.

3.6 Variations on $\operatorname{sIgM}^{+}$B lymphocytes in peripheral blood, spleen, and head kidney after immunization

In pBudCE4.1-OmpK, pBudCE4.1-OmpK-CCL4, and pBudCE4.1-OmpK-CCL19 (p-OmpK, p-OmpKCCL4, and p-OmpK-CCL19) groups, the results showed that the percentage of $\operatorname{sIgM}^{+} B$ lymphocytes in PBL, spleen, and head kidney increased significantly in $2^{\text {nd }}$ or $3^{\text {rd }}$ week, peaked in the $6^{\text {th }}$ week, and then 

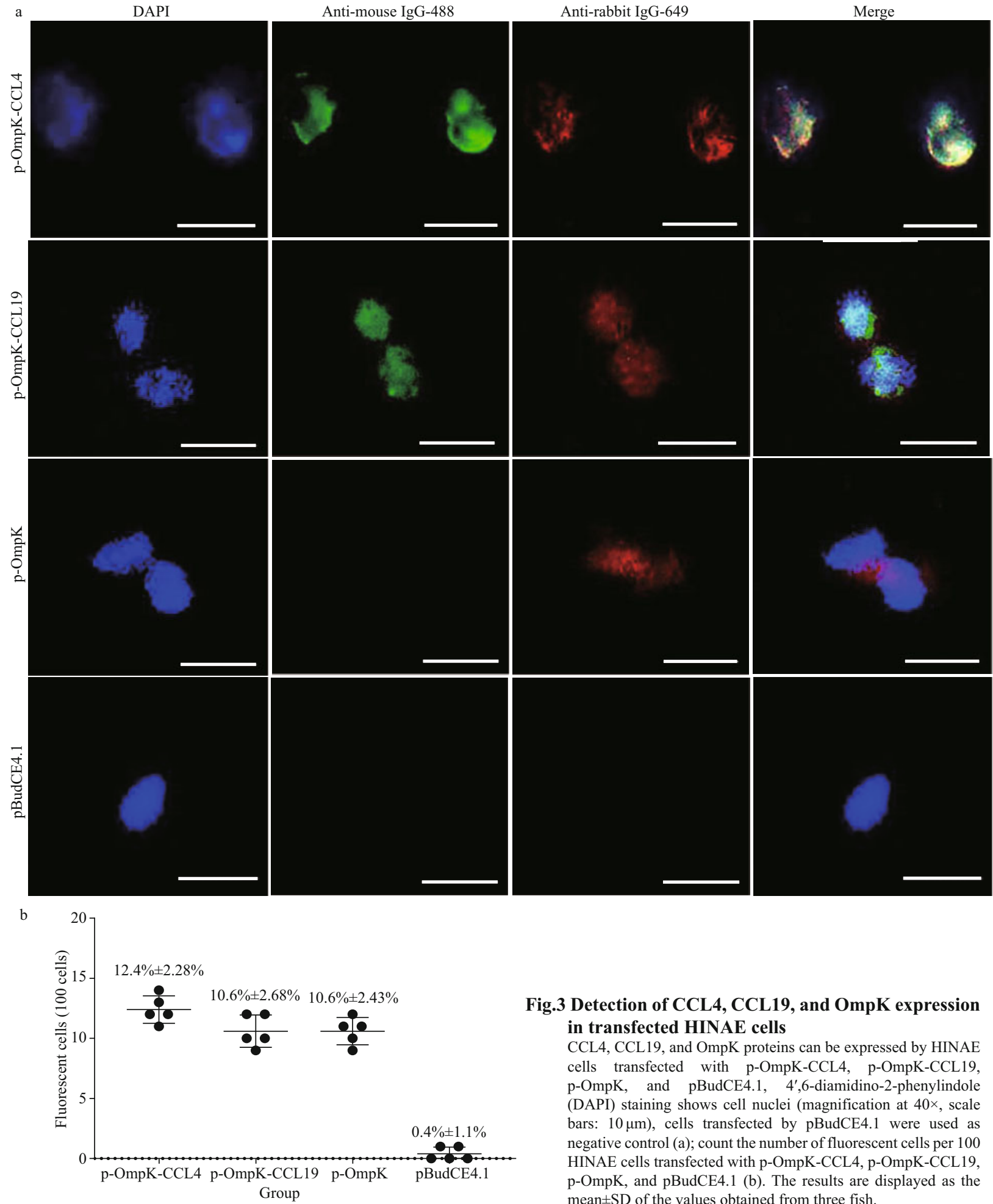

Fig.3 Detection of CCL4, CCL19, and OmpK expression in transfected HINAE cells

CCL4, CCL19, and OmpK proteins can be expressed by HINAE cells transfected with p-OmpK-CCL4, p-OmpK-CCL19, p-OmpK, and pBudCE4.1, 4',6-diamidino-2-phenylindole (DAPI) staining shows cell nuclei (magnification at $40 \times$, scale bars: $10 \mu \mathrm{m}$ ), cells transfected by pBudCE4.1 were used as negative control (a); count the number of fluorescent cells per 100 HINAE cells transfected with p-OmpK-CCL4, p-OmpK-CCL19, $\mathrm{p}$-OmpK, and pBudCE4.1 (b). The results are displayed as the mean $\pm \mathrm{SD}$ of the values obtained from three fish.

began to decline (Fig.8).

In PBL, spleen, and head kidney of p-OmpK-CCL4 and p-OmpK-CCL19 groups, the percentage of $\operatorname{sIgM}^{+}$ B lymphocytes was $23.9 \% \pm 0.62 \%$ and $23.9 \% \pm 0.98 \%$, $14.8 \% \pm 0.46 \%$ and $15.9 \% \pm 0.60 \%, 23.4 \% \pm 0.44 \%$ and $10.9 \% \pm 0.65 \%$ in the $6^{\text {th }}$ week after immunization,

respectively. It was higher in both p-OmpK-CCL4 and $\mathrm{p}$-OmpK-CCL19 groups than those in the $\mathrm{p}$-OmpK group $(P<0.05)$. In addition, the percentage of $\operatorname{sIgM}^{+}$ B lymphocytes of the head kidney in p-OmpK-CCL4 group was higher than the $\mathrm{p}$-OmpK-CCL19 group in the $6^{\text {th }}$ and $7^{\text {th }}$ weeks after immunization $(P<0.05)$. 


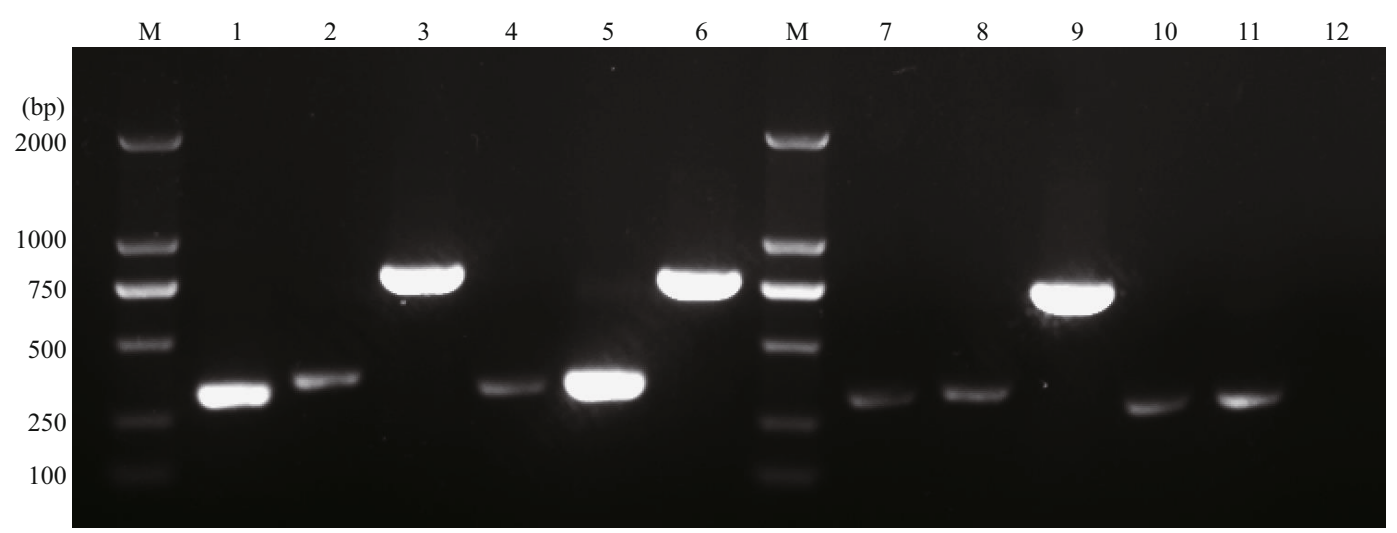

Fig.4 The transcription of p-OmpK-CCL4, p-OmpK-CCL19, p-OmpK, and pBudCE4.1 in flounder detected by RT-PCR on the $3^{\text {rd }}$ day post-immunization

The samples from p-OmpK-CCL4 and p-OmpK-CCL19 groups were amplified with the chemokine- and OmpK-specific primers. Lane M: DNA marker; lanes 1,2, and 3: the transcription level of CCL4, CCL19, and OmpK genes in p-OmpK-CCL4-injected fish; lanes 4, 5, and 6: the transcription level of CCL4, CCL19 and OmpK genes in p-OmpK-CCL19-injected fish; lanes 7, 8, and 9: the transcription level of CCL4, CCL19, and OmpK genes in p-OmpK-injected fish; lanes 10, 11, and 12: the transcription level of CCL4, CCL19, and OmpK genes in pBudCE4.1-injected fish.

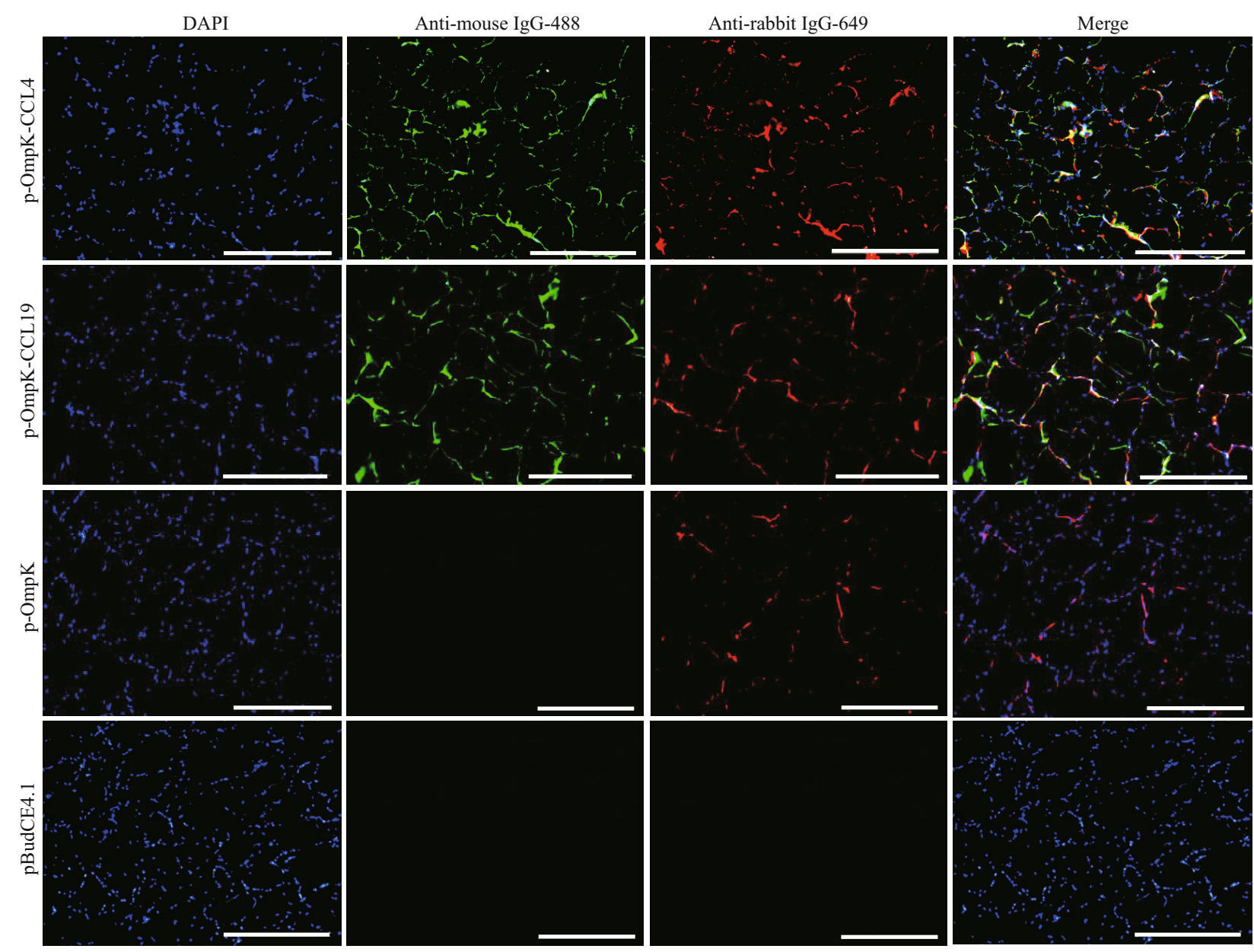

Fig.5 Detection of CCL4, CCL19, and OmpK expression in vaccinated fish

Three days after immunization, sections of the muscles were incubated with mouse monoclonal antibody against His-tag and rabbit polyclonal antibody against rOmpK-GST, and then incubated with goat anti-mouse antibody coupled to Alexa 488 and goat anti-rabbit antibody coupled to Alexa 649. IFA was analyzed by epifluorescence microscopy at a magnification of 10×. Scale bars: $500 \mu \mathrm{m}, 4^{\prime}, 6$-diamidino-2-phenylindole (DAPI) staining shows cell nuclei. Sections from the pBudCE4.1 group were used as the negative control. 


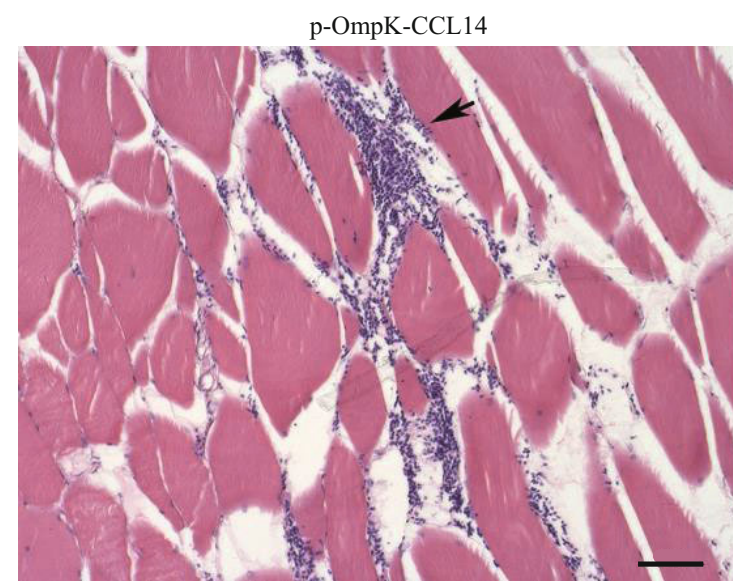

$\mathrm{p}-\mathrm{OmpK}$

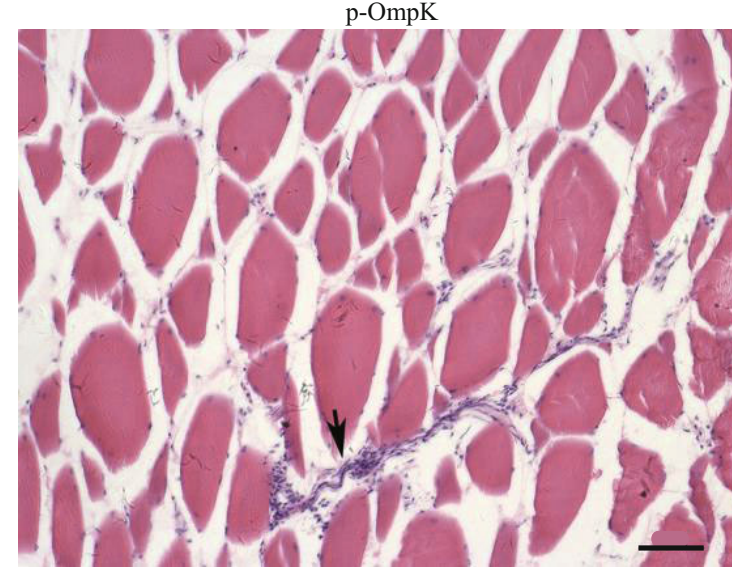

Fig.6 Injection of recombinant plasmids leads to local recruitment of leucocytes

pBudCE4.1
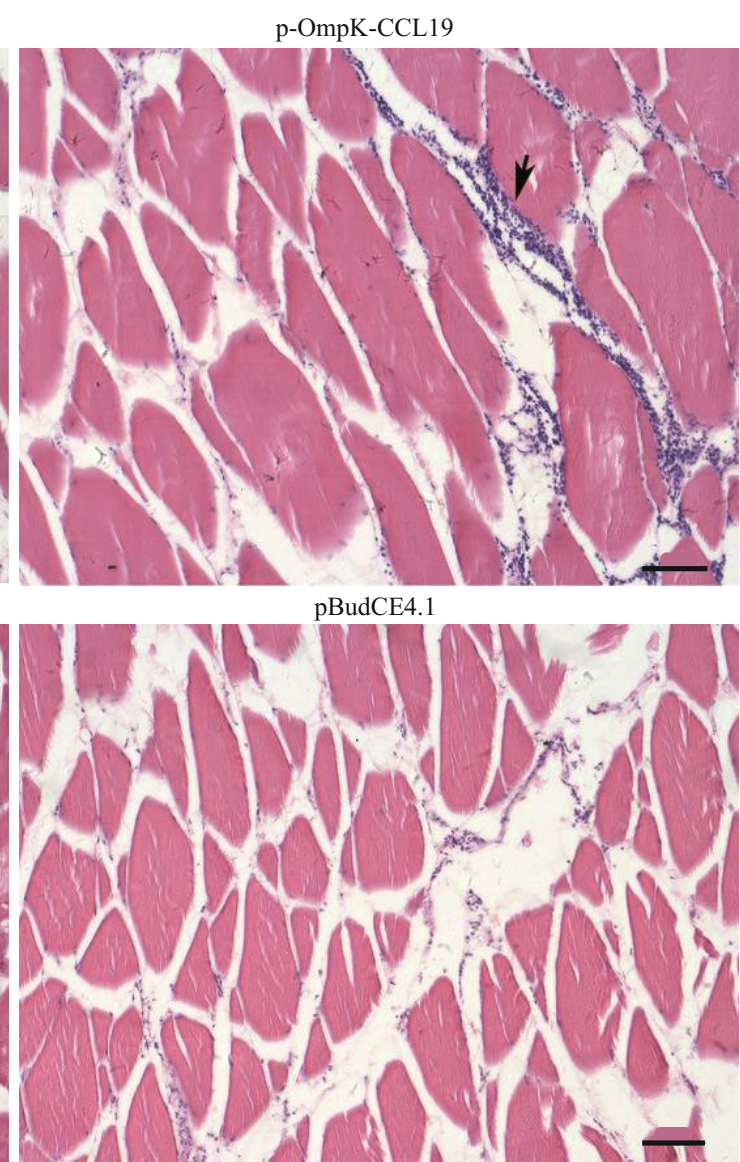

The above results indicated that CCL4 and CCL19 can further increase the percentage of $\operatorname{sIgM}^{+} \mathrm{B}$ lymphocytes based on the OmpK DNA vaccine.

\subsection{Expression of immune-related genes}

In muscles of $\mathrm{p}$-OmpK-CCL4 and $\mathrm{p}$-OmpKCCL19 groups, the expression profiles of IFN- $\gamma$, GATA-3, IL-2, CD83, MHC I, and MHC II genes significantly increased after immunization and significantly higher than that of the pBudCE4.1 group. The expression profiles of IFN- $\gamma$, IL-2, CD83, MHC I, and MHC II genes were also significantly higher than that of the p-OmpK group (Fig.9a; $P<0.05$ ), but the expression profiles of CD4-1, CD4-2, CD8 $\beta$, and IL-6 were not significantly different from that of the control groups (p-OmpK and pBudCE4.1) (data not shown).

In the spleen, there was no significant difference in the expression profiles of IL- 6 genes among the four groups, the expression profiles of CD8 $\beta$, IFN- $\gamma$, IgM, IL-2, CD4-1, CD4-2, MHC I, and MHC II genes in p-OmpK-CCL4 and p-OmpK-CCL19 groups were significantly higher than that of pBudCE4.1 group, and the expression profiles of IgM, IL-2, CD4-1, CD4-2, MHC I, and MHC II genes were significantly higher than that of the $\mathrm{p}-\mathrm{OmpK}$ group after immunization (Fig.9b, $P<0.05$ ).

In the head kidney, the relative expressions of IL-6, IFN- $\gamma$, IL-2, IgM, CD4-1, CD4-2, CD8 $\beta$, MHC I, and MHC II genes in p-OmpK-CCL4 and p-OmpKCCL19 groups were significantly higher than that of the pBudCE4.1 group after immunization, and the expression profiles of IL-2, CD4-1, CD4-2, MHC I, and MHC II genes were significantly higher than that of the p-OmpK group (Fig.9c; $P<0.05$ ).

\subsection{Relative percentage survival}

After the challenge, flounder in p-OmpK-CCL4 and $\mathrm{p}-\mathrm{OmpK}-\mathrm{CCL} 19$ groups began to die on the $1^{\text {st }}$ $2^{\text {nd }}$ day and died quickly during the $3^{\text {rd }}-10^{\text {th }}$ days, and then the mortalities remained stable till the end of the experiment. However, flounder in $\mathrm{p}-\mathrm{OmpK}$ and pBudCE4.1 groups died almost every day in 14 days after the challenge. The cumulative mortality rates of 

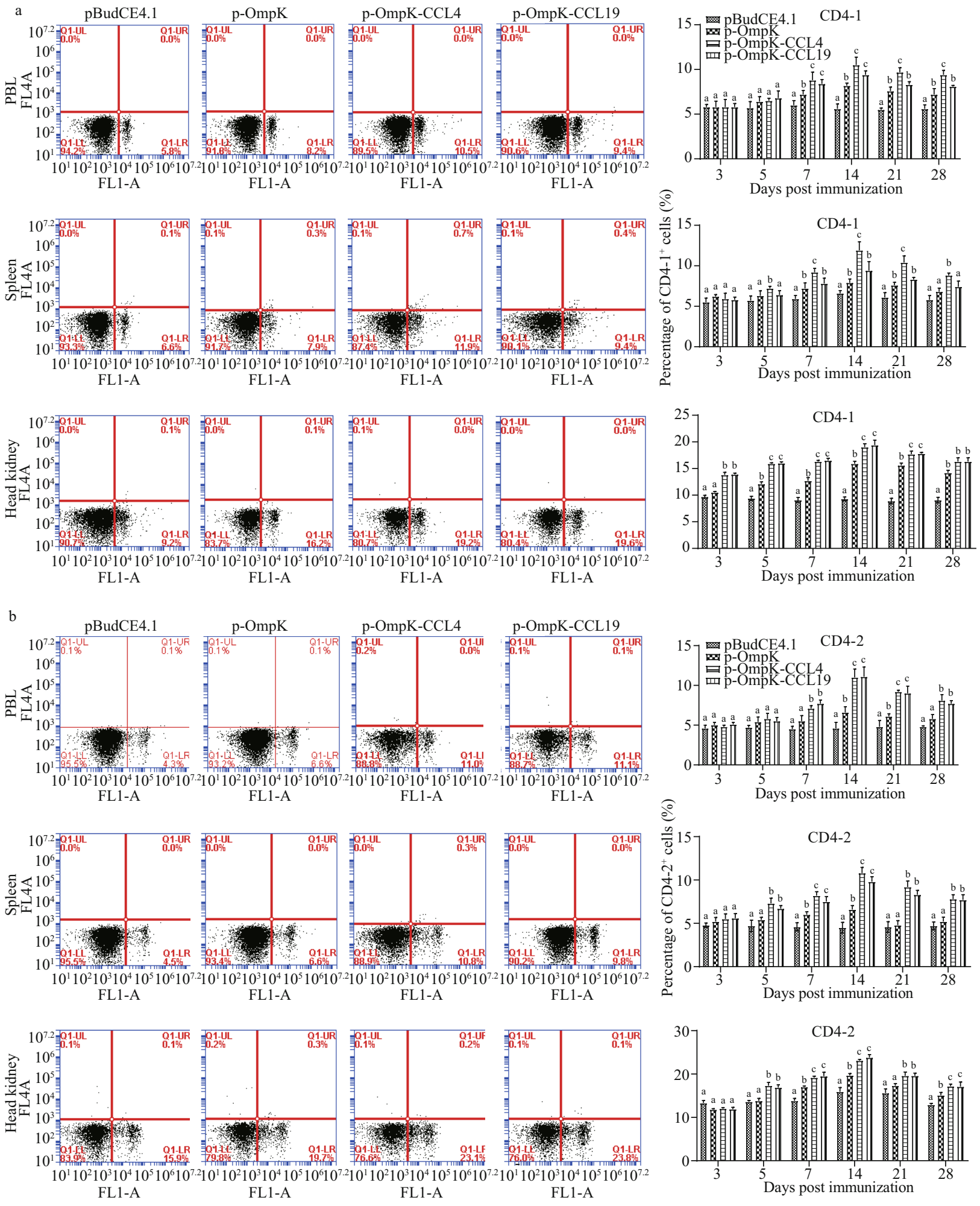

Fig.7 The $T$ lymphocytes immune response induced by recombinant plasmids

FCM assay investigating the percentage of $\mathrm{CD}^{-1}-1^{+}$(a) and CD4-2 (b) T lymphocytes in PBL, spleen, and head kidney of flounder. Plots show the percentage of CD4-1+ (a) and CD4-2 (b) T lymphocytes in pBudCE4.1-, p-OmpK-, p-OmpK-CCL4-, and p-OmpK-CCL19-injected fish on day 14 post-immunization. Histograms show the changes of CD4-1 $1^{+}$(a) and $\mathrm{CD}_{-1}-2^{+}$(b) T lymphocytes after immunization. Results are displayed as mean $\pm \mathrm{SD}$ of three fish. The different letters on the bar represent the statistical significance $(P<0.05)$.

p-OmpK-CCL4, p-OmpK-CCL19, and p-OmpK groups were significantly lower than those in the
pBudCE4.1 group, which were $23.3 \%, 33.3 \%$, and $53.3 \%$, respectively, conferred to RPS of $74.1 \%$, 

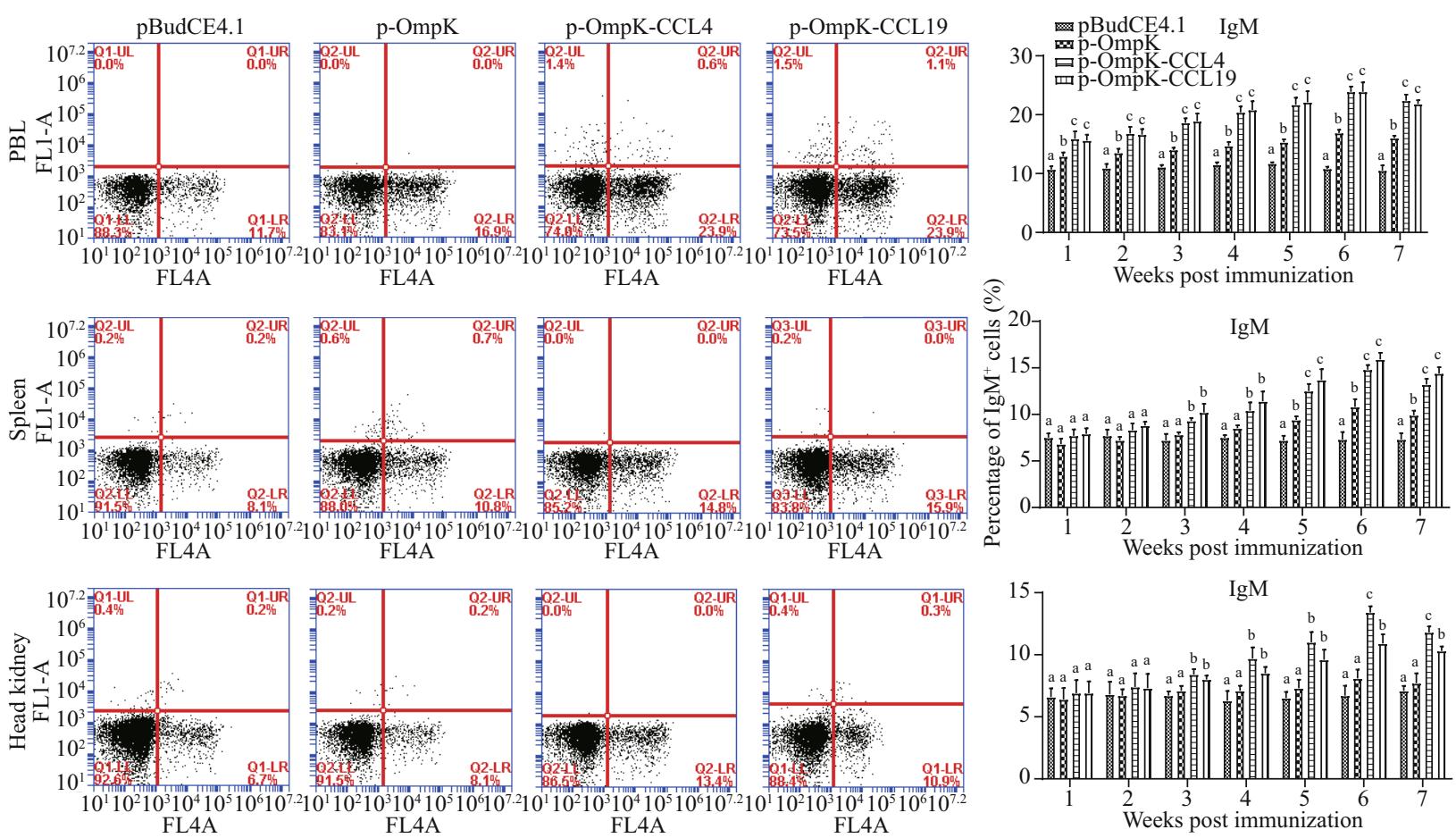

Fig.8 The sIgM+ B lymphocytes immune response induced by recombinant plasmids

FCM assay investigating the percentage of $\operatorname{sIgM}^{+}$B lymphocytes in PBL, spleen, and head kidney of flounder. Plots show the percentage of sIgM $\mathrm{B}^{+}$ lymphocytes in pBudCE4.1-, p-OmpK-, p-OmpK-CCL4-, and p-OmpK-CCL19-injected fish in week 6 post-immunization. Histograms show the changes of $\operatorname{sIgM}^{+} \mathrm{B}$ lymphocytes after immunization. Results are displayed as mean $\pm \mathrm{SD}$ of three fish. The different letters on the bar represent the statistical significance $(P<0.05)$.

$63.3 \%$, and $40.8 \%$ (Fig. 10a). Additionally, the results of Log-Rank test revealed that survivals of p-OmpkCCL4, p-OmpK-CCL19, and p-OmpK groups were significantly higher than the pBudCE4.1 group, and there was no difference in mortality rates among p-OmpK-CCL4, p-OmpK-CCL19, and p-OmpK groups (Fig.10b). For all challenge trials, examination of moribund fish indicated that $V$. anguillarum were the only types of bacterial strains isolated from the liver, spleen, and the head-kidney tissue of challenged fish, respectively, suggesting that mortalities were caused by the challenging bacteria.

It should be emphasized that the RPS was calculated on the $14^{\text {th }}$ day after the challenge, and the results might have been different if the challenge had been extended to 14 days or more.

\section{DISCUSSION}

Outer membrane protein is an important pathogenic factor of gram-negative bacteria and plays a key role in bacterial infection and colonization (Abdelhamed et al., 2017). Outer membrane protein exists in a variety of pathogenic bacteria, and because it can be easily recognized by the immune system of fish, it is considered to be an important factor that stimulates fish to produce immune responses ( $\mathrm{Li}$ et al., 2014). Researchers have shown that the outer membrane protein of bacteria is an antigenic protein that locates on the surface of bacteria, and it has the potential to become a candidate vaccine for bacteria, such as $V$. anguillarum, Vibrio harveyi, Edwardsiella tarda (Hamod et al., 2012; Liu et al., 2016a; Zhu et al., 2019). Moreover, some studies have shown that the outer membrane of pathogenic bacteria can be used as a DNA vaccine or subunit vaccine to induced specific antibodies and provided protection against pathogenic bacteria (Vazquez-Juarez et al., 2005; Kumar et al., 2007; Liu et al., 2017a). In 1991, it was first reported that antigens could be expressed by recombinant plasmids in fish muscles (Hansen et al., 1991), and DNA vaccines of fish are still widely studied today. DNA vaccines have many advantages, such as being easy to produce and store, and relatively inexpensive, moreover, DNA vaccines can also induce strong and durable humoral and cellular immune responses (Adel et al., 2016; Zahm et al., 2017; Lee et al., 2018). However, in terms of animal safety and environmental protection, DNA vaccines have some potential and unknown risks. 


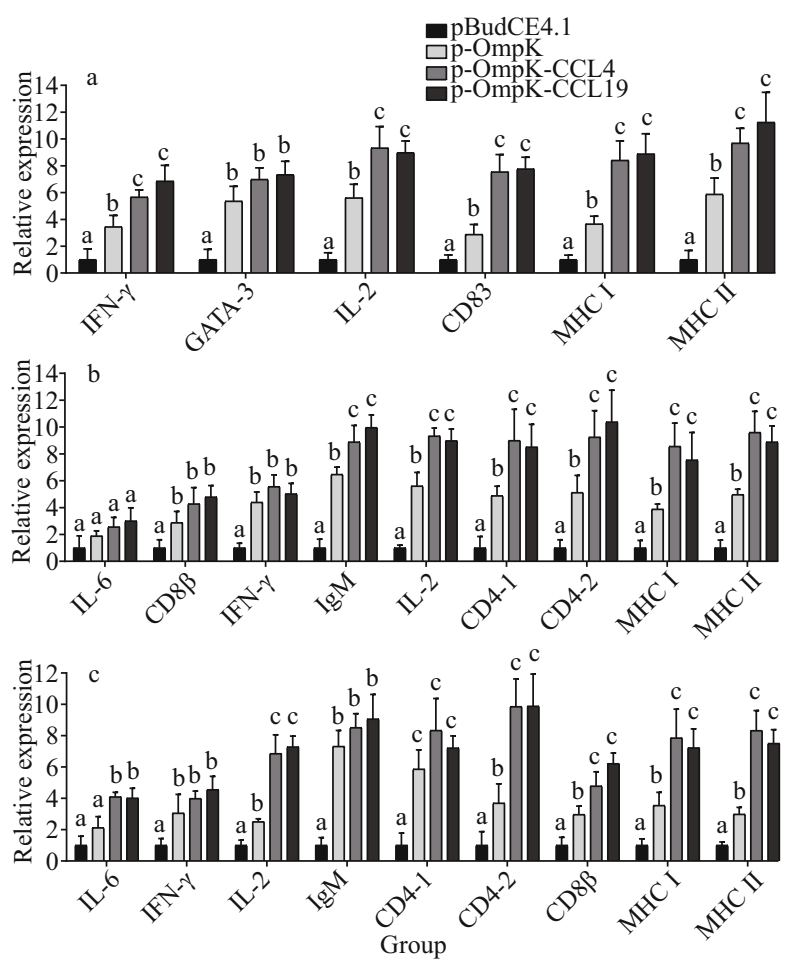

Fig.9 Detection of the expression of immune-related genes induced by recombinant plasmids

The qRT-PCR results of muscles (a), spleen (b), and head kidney (c) on the $7^{\text {th }}$ post-vaccination day by qRT-PCR. The mRNA level of each gene was normalized to that of $18 \mathrm{~S}$ rRNA. For each immunerelated gene, the mRNA level in muscle from pBudCE4.1-injected flounder was set as 1 . The $y$-axis represent the mRNA abundance relative to the expression in fish injected with the pBudCE4.1. The results are displayed as the mean $\pm \mathrm{SD}$ of the values obtained from three fish. Different letters (a, b, and c) on the bars indicate statistically significant differences $(P<0.05)$ compared to the same gene in each group.

Our previous study has demonstrated that the OmpK gene of $V$. anguillarum in the form of recombinant plasmids and injected it into the flounder, resulting in an RPS of $50 \%$ in flounder (Xu et al., 2019a). Although the OmpK-based DNA vaccine can induce humoral and cellular immune responses in flounder, and higher levels of antibodies can be detected after immunization, but it did not provide the flounder with ideal protection. Many factors affect the protection of DNA vaccines, such as the type of expression vector, use of adjuvants, different inoculation methods, inoculation routes, and environmental factors (Cheng et al., 1993; Fynan et al., 1993). The use of adjuvants is a simple, convenient, and effective method to improve the protection of vaccines. Common adjuvants include Freund's adjuvant, aluminum salt adjuvant. Previous research has demonstrated that the OmpW subunit vaccine of E. tarda formulated with Freund's complete adjuvant can result in an RPS of $60 \%$ in flounder (Liu et al.,

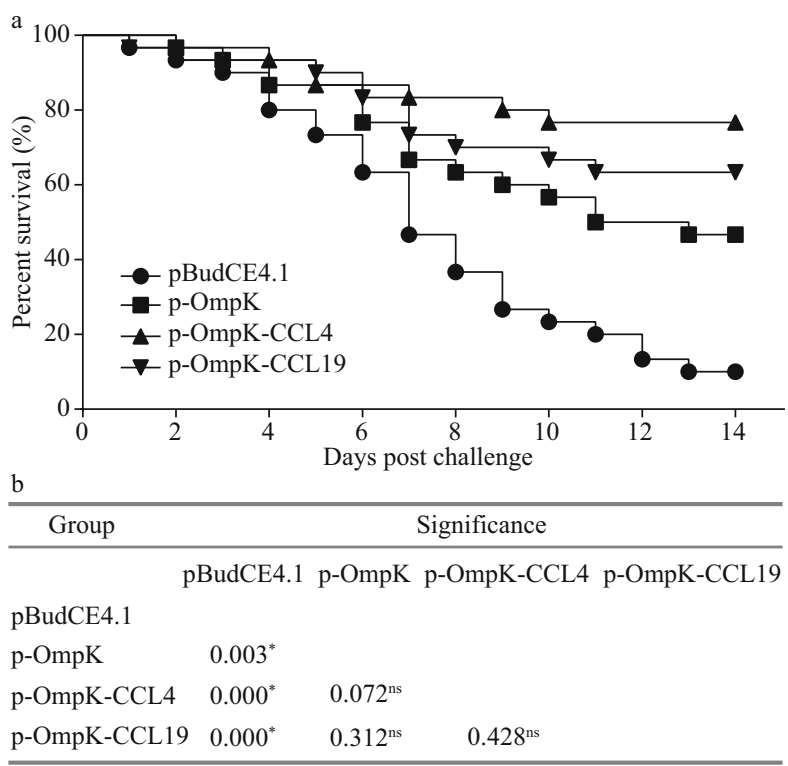

Fig.10 Survival percentage of immunized fish after challenged with $V$. anguillarum

In the $7^{\text {th }}$ week post-immunization, flounder were challenged by $1.0 \times 10^{7} \mathrm{CFU}$ live $V$. anguillarum intraperitoneally and the survival percentage was calculated at the end of the monitored period (a). Log-Rank test was used to detect the difference among groups (b). " "”" indicates the significant difference $(P<0.05)$, " "ns" indicate no significant difference.

2017b). However, compared with the most common adjuvants in fish farming (aluminum salt adjuvants and oil adjuvants), cytokines as adjuvants have advantages in initiating the expression of costimulatory molecules and the polarization of antigen-presenting cells (Tovey and Lallemand, 2010). Xu et al. (2020) pointed out that CCL3/CCL4/CCL19/CCL21 as adjuvants for VAA-based DNA vaccine could effectively protect flounder against $V$. anguillarum after immunization.

The pBudCE4.1 plasmid is a eukaryotic dual expression vector with $\mathrm{CMV}$ and EF-1 $\alpha$ promoters, enabling the simultaneous expression of two foreign genes inserted into the plasmid. Research on mice showed that the genes of mycolyl-transferase Ag85A and phosphate transport receptor PstS-3 from Mycobacterium tuberculosis were inserted into the pBudCE4.1 plasmid, and the antigens expressed by recombinant plasmid were proved to have good immunogenicity (Romano et al., 2006). pBudCE4.1 plasmid as a vector, intramuscular injection of naked DNA plasmids encoding proinsulin and pancreatic regeneration III protein can reduce the incidence of hyperglycemia and diabetes in mice (Hou et al., 2011). In this research, the OmpK gene of $V$. anguillarum and the CCL4/CCL19 genes of flounder were inserted into the pBudCE4.1 vector 
under the control of EF-1 $\alpha$ and CMV promoters, respectively, to generate two bicistronic plasmids that co-expressed OmpK and CCL4/CCL19. To prove that the foreign genes were inserted into the pBudCE4.1 plasmid successfully, double digestion and agarose gel electrophoresis assay were performed. The results proved that these foreign genes were successfully inserted into the plasmids. In addition, DNA sequencing results showed that the foreign genes were accurate. Bright green and red fluorescence can be observed by IFA in HINAE cells transfected with recombinant plasmids, which revealed that these recombinant plasmids can be successfully expressed in vivo and in vitro.

Chemokines are small secreted proteins and usually range between $8-12 \mathrm{kDa}$, they belong to the subfamily of chemokine cytokines, which play a key role in mediating leukocyte migration, regulating immune responses and differentiation of the recruited cells (Moser et al., 2004). To date, a variety of chemokines have been reported in mammals and teleost. The chemokine CC-motif ligand 4 (CCL4) is a member of the $\mathrm{CC}$ chemokine subfamily, it is also known as MIP-1 $\beta$ because it was first discovered from the macrophages stimulated by lipopolysaccharide (LPS) (Chensue et al., 1996). CCL4 in mammals is usually secreted by antigen-presenting cells (APC), such as B cells, T cells, macrophages, and DC, and it binds to its specific receptor CCR5 to induce monocytes, migration, and recruitment of phages and Th1 cells (Bystry et al., 2001). Although CCL4 has been well studied in mammals, it has been identified in only a few species of fish, and few kinds of research on CCL4 as an adjuvant for fish vaccines (Xu et al., 2020). Mice as an immune model and the pcDNA3.1 encoding the CCL4 gene as an adjuvant for rabies virus glycoprotein DNA vaccine, the results found that CCL4 can improve the immune response against rabies virus in mice after vaccination and CCL4 had the potential to be an adjuvant for rabies virus DNA vaccine (Pinto et al., 2003). p-CCL4 was successfully constructed and inoculated into flounder by intramuscular injection in the experiment. After immunization, the percentage of $\mathrm{T}$ and $\mathrm{B}$ lymphocyte subsets, the expression differences of immune-related genes, and the RPS were detected and the results showed that there was no significant difference between the $\mathrm{p}-\mathrm{CCL} 4$ group and the $\mathrm{pBudCE} 4.1$ group (data not shown). In this paper, p-OmpK-CCL4 was injected into flounder and results showed that the percentage of CD4-1+ and CD4-2 $2^{+} \mathrm{T}$ lymphocytes, and $\operatorname{sIgM}^{+} \mathrm{B}$ lymphocytes were significantly higher than those in pBudCE4.1 and p-OmpK groups after immunization, which proved that CCL 4 as an adjuvant for OmpK-based DNA vaccine can significantly improve the cellular immune response of flounder. And it can recruit a lot of leucocytes at the injection site post-immunization and conferred an RPS of $74.1 \%$ against $V$. anguillarum, which revealed that CCL4 can further enhance the recruitment of leucocytes based on the OmpK DNA vaccine and can provide better protection. Moreover, the expression profiles of all immune-related genes except IFN- $\gamma$ in p-OmpK-CCL4 groups were significantly higher than that of control groups.

The chemokine CC-motif ligand 19 (CCL19) also belongs to the $\mathrm{CC}$ chemokine subfamily. In mammals, CCL19 is called MIP-3 3 or ELC, it can be synthesized and secreted by many immune cells, such as macrophages, neutrophils, NK cells, and DC (Yoshida et al., 1997; Katou et al., 2003). CCL19 is abundantly expressed in thymus and lymph nodes and secreted by DC during activation and migration (Radstake et al., 2005). CCR7 is the specific receptor for CCL19, and it is induced upon activation of DC, that is, by external infectious stimuli via TLR (Stewart and Smyth, 2008). CCL19 increases the chance of interaction between $\mathrm{DC}, \mathrm{T}$ cells, and $\mathrm{B}$ cells in secondary lymphatic tissue, thus regulates the primary or secondary adaptive immune response (Nguyen-Hoai et al., 2012). CCL19 has only been studied in a few fish species, including flounder, turbot (Scophthalmus maximus), striped murrel (Channa striatus), and ayu (Plecoglossus altivelis) (Chen et al., 2013; Arockiaraj et al., 2015; Zhang et al., 2015; Fu et al., 2017). CCL19 has been abundantly studied in mammals, but there is not much investigation of CCL19 as a vaccine adjuvant in fish. Nguyen-Hoai et al. (2012) showed that recombinant plasmid encoding the human CCL19 gene and immunized mouse tumor models with the anti-tumor DNA vaccine $\mathrm{pVax} / \mathrm{E} 2 \mathrm{~A}$ by gene gun, the results showed that CCL19 can enhance protection of vaccine and B cells function as APC. Yan et al. (2016) pointed that a nasal adjuvant composed of CCL17 and CCL19 is used together with an anti-caries DNA vaccine, they can recruit more mature DC to secondary lymphoid tissues, induce the body to produce high titer antibodies, and reduce $\mathrm{S}$ mutants infection in rodents after vaccination. The results of $\mathrm{T}$ and B lymphocyte subsets percent, the expression differences of immune-related genes, and the RPS in 
p-CCL19-injected fish also showed that there was no significant difference between the p-CCL19 group and the pBudCE4.1 group after immunization (data not shown). In this study, p-OmpK-CCL19 was injected into the flounder intramuscularly, and the results of FCM were similar to those of the p-OmpKCCL4 group, the percentage of T, B lymphocytes subpopulations peaked in the $6^{\text {th }}$ weeks after immunization, respectively. The percentage of CD4-1 $1^{+}$ and CD4-2 $2^{+} \mathrm{T}$ lymphocytes in PBL and spleen was lower than in the p-OmpK-CCL4 group but higher than in head kidney of the p-OmpK-CCL4 group. Moreover, p-OmpK-CCL19 also recruited a lot of leucocytes at the injection site compared with $\mathrm{p}$-OmpK and pBudCE4.1 plasmids, the results were similar to the p-OmpK-CCL4 group as described above. Both p-OmpK-CCL4 and p-OmpK-CCL19 can induce leucocytes recruitment in local muscle tissue, various cells including neutrophils, mononuclear macrophages, lymphocytes, etc. They can be recruited at the injection site, but the mechanism of leucocytes recruitment and the types of cells recruited by $\mathrm{p}-\mathrm{OmpK}-\mathrm{CCL} 4$ and $\mathrm{p}-\mathrm{OmpK}$ CCL19 will be further studied. The relative expression of immune-related genes was also close to that of the p-OmpK-CCL4 group and p-OmpK-CCL19 provided an RPS of $63.3 \%$ against $V$. anguillarum.

It is worth noting that the percentage of CD4- $1^{+}$ and CD4-2 $2^{+} \mathrm{T}$ lymphocytes of flounder in $\mathrm{p}-\mathrm{OmpK}$ CCL4 and p-OmpK-CCL19 groups were almost the same after immunization, but there is a difference in the number of CD4-1 $1^{+}$and CD4-2 $2^{+}$lymphocytes. In fact, in contrast with the situation of tetrapod, which possesses a single CD4 gene, flounder contain two CD4 genes, CD4-1 and CD4-2. Research has shown that the CD4-1+ and CD4-2+ $\mathrm{T}$ lymphocytes of teleost are functionally similar to those of tetrapod $\mathrm{CD} 4^{+} \mathrm{T}$ lymphocytes, but the functional differences between the CD4- $1^{+}$and CD4-2+ $\mathrm{T}$ lymphocytes of teleost are still unclear (Takizawa et al., 2016). Mouse-anti flounder CD4-1/CD4-2 monoclonal antibodies were produced in our lab previously and can be used to identify the CD4-1+ and CD4-2+ $\mathrm{T}$ lymphocytes of flounder (Tian et al., 2019). CD4-1/CD4-2, CD4-1, CD4-2 molecules can be expressed by immune cells according to the transcript analysis of sorted CD4- $1^{+}$ cells in Ginbuna crucian carp and fugu (Kono and Korenaga, 2013; Somamoto et al., 2014). Thus CD41 and CD4-2 were not fully co-expressed, which may explain the different percentages of CD4- ${ }^{+}$and CD4$2^{+} \mathrm{T}$ lymphocytes after immunization in this paper.
Both CD4-1 and CD4-2 may function as Th cells suggested by a study, therefore it might show the different immune role of the two subsets (Edholm et al., 2007).

\section{CONCLUSION}

In this research, two bicistronic plasmids (p-OmpKCCL4 and p-OmpK-CCL19) were constructed successfully, and p-OmpK and pBudCE4.1 as control, their immune effects were detected after immunization. The results showed that the plasmids could be transcribed and expressed in cell lines and muscles of flounder. After immunization, p-OmpK-CCL4 and p-OmpK-CCL19 induced higher expressions of $\mathrm{CD} 4-1^{+}$and $\mathrm{CD} 4-2^{+} \mathrm{T}$ lymphocytes, and $\operatorname{sIgM}^{+} \mathrm{B}$ lymphocytes compared with control groups $(P<0.05)$, and recruited more leucocytes to the injection site. In addition, p-OmpK-CCL4 and p-OmpK-CCL19 upregulated the expressions of all immune-related genes except IL-6 in muscle, spleen, and head kidney of flounder, which were significantly higher than those in the pBudCE4.1 group $(P<0.05)$, and conferred an RPS of $74.1 \%$ and $63.3 \%$, respectively, higher than p-OmpK alone (40.8\%). In summary, this study indicated that CCL4 and CCL19 have significant adjuvant effects on OmpK-based DNA vaccine, and could be employed as efficient adjuvants in aquaculture.

\section{DATA AVAILABILITY STATEMENT}

All data generated or analyzed during this study are included in this article.

\section{DECLARATION OF INTEREST STATEMENT}

The authors declare that they have no known competing financial interests or personal relationships that could have appeared to influence the work reported in this paper.

\section{References}

Abdelhamed H, Ibrahim I, Nho S W, Banes M M, Wills R W, Karsi A, Lawrence M L. 2017. Evaluation of three recombinant outer membrane proteins, OmpA1, Tdr, and $\mathrm{TbpA}$, as potential vaccine antigens against virulent Aeromonas hydrophila infection in channel catfish (Ictalurus punctatus). Fish \& Shellfish Immunology, 66: 480-486, https://doi.org/10.1016/j.fsi.2017.05.043.

Adel M, Yeganeh S, Dadar M, Sakai M, Dawood M A O. 2016. Effects of dietary Spirulina platensis on growth 
performance, humoral and mucosal immune responses and disease resistance in juvenile great sturgeon (Huso huso Linnaeus, 1754). Fish \& Shellfish Immunology, 56: 436-444, https://doi.org/10.1016/j.fsi.2016.08.003.

Ahmadivand S, Soltani M, Behdani M, Evensen Ø, Alirahimi E, Soltani E, Hassanzadeh R, Ashrafi-Helan J. 2018. VP2 (PTA motif) encoding DNA vaccine confers protection against lethal challenge with infectious pancreatic necrosis virus (IPNV) in trout. Molecular Immunology, 94: 61-67, https://doi.org/10.1016/j.molimm.2017.12.015.

Alejo A, Tafalla C. 2011. Chemokines in teleost fish species. Developmental \& Comparative Immunology, 35(12): 1215-1222, https://doi.org/10.1016/j.dci.2011.03.011.

Amend D F. 1981. Potency testing of fish vaccine. Developments in Biological Standardization, 49: 447454.

Arockiaraj J, Bhatt P, Harikrishnan R, Arasu M V, Al-Dhabi N A. 2015. Molecular and functional roles of $6 \mathrm{C} \mathrm{CC}$ chemokine 19 in defense system of striped murrel Channa striatus. Fish \& Shellfish Immunology, 45(2): 817-827, https://doi.org/10.1016/j.fsi.2015.06.001.

Bonecchi R, Galliera E, Borroni E M, Corsi M M, Locati M, Mantovani A. 2009. Chemokines and chemokine receptors: an overview. Frontiers in Bioscience, 14(2): 540-551, https://doi.org/10.2741/3261.

Bonecchi R, Graham G J. 2016. Atypical chemokine receptors and their roles in the resolution of the inflammatory response. Frontiers in Immunology, 7: 224, https://doi. org/10.3389/fimmu.2016.00224.

Bystry R S, Aluvihare V, Welch K A, Kallikourdis M, Betz A G. 2001. B cells and professional APCs recruit regulatory T cells via CCL4. Nature Immunology, 2(12): 1126-1132, https://doi.org/10.1038/ni735.

Chang C J. 2020. Immune sensing of DNA and strategies for fish DNA vaccine development. Fish \& Shellfish Immunology, 101: 252-260, https://doi.org/10.1016/j. fsi.2020.03.064.

Chen C, Hu Y H, Xiao Z Z, Sun L. 2013. SmCCL19, a CC chemokine of turbot Scophthalmus maximus, induces leukocyte trafficking and promotes anti-viral and antibacterial defense. Fish \& Shellfish Immunology, 35(5): 1677-1682, https://doi.org/10.1016/j.fsi.2013.08.020.

Cheng L, Ziegelhoffer P R, Yang N S. 1993. In vivo promoter activity and transgene expression in mammalian somatic tissues evaluated by using particle bombardment. Proceedings of the National Academy of Sciences of the United States of America, 90(10): 4455-4459, https://doi. org/10.1073/pnas.90.10.4455.

Chensue S W, Warmington K S, Ruth J H, Sanghi P S, Lincoln P, Kunkel S L. 1996. Role of monocyte chemoattractant protein-1 (MCP-1) in Th1 (mycobacterial) and Th2 (schistosomal) antigen-induced granuloma formation: relationship to local inflammation, Th cell expression, and IL-12 production. The Journal of Immunology, 157(10): 4602-4608.

Choi M G, Kim M S, Choi T J, Kim K H. 2019. Effect of CXCL12-expressing viral hemorrhagic septicemia virus replicon particles on leukocytes migration and vaccine efficacy in olive flounder (Paralichthys olivaceus). Fish \& Shellfish Immunology, 89: 378-383, https://doi.org/10. 1016/j.fsi.2019.04.018.

Cui Z R. 2005. DNA vaccine. Advances in Genetics, 54: 257289, https://doi.org/10.1016/S0065-2660(05)54011-2.

Edholm E S, Stafford J L, Quiniou S M, Waldbieser G, Miller N W, Bengtén E, Wilson M. 2007. Channel catfish, Ictalurus punctatus, CD4-like molecules. Developmental \& Comparative Immunology, 31(2): 172-187, https://doi. org/10.1016/j.dci.2006.05.012.

Esche C, Stellato C, Beck L A. 2005. Chemokines: key players in innate and adaptive immunity. Journal of Investigative Dermatology, 125(4): 615-628, https://doi.org/10.1111/ j.0022-202X.2005.23841.x.

Fu Q, Yang Y J, Li C, Zeng Q F, Zhou T, Li N, Liu Y, Li Y, Wang X Z, Liu S K, Li D J, Liu Z J. 2017. The chemokinome superfamily: II. The $64 \mathrm{CC}$ chemokines in channel catfish and their involvement in disease and hypoxia responses. Developmental \& Comparative Immunology, 73: 97-108, https://doi.org/10.1016/j. dci.2017.03.012.

Fynan E F, Webster R G, Fuller D H, Haynes J R, Santoro J C, Robinson H L. 1993. DNA vaccines: protective immunizations by parenteral, mucosal, and gene-gun inoculations. Proceedings of the National Academy of Sciences of the United States of America, 90(24): 1147811482, https://doi.org/10.1073/pnas.90.24.11478.

Gaertner F H, Babiuk L A, Mutwiri G, Armstrong J M, Griebel P J. 2009. Amended recombinant cells (ARCs ${ }^{\mathrm{TM}}$ ) expressing bovine IFN- $\gamma$ : An economical and highly effective adjuvant system. Vaccine, 27(9): 1377-1385, https://doi.org/10.1016/j.vaccine.2008.12.049.

Hamod M A, Nithin M S, Shukur Y N, Karunasagar I, Karunasagar I. 2012. Outer membrane protein K as a subunit vaccine against $V$. anguillarum. Aquaculture, 354-355: 107-110, https://doi.org/10.1016/j.aquaculture. 2012.03.033.

Hansen E, Fernandes K, Goldspink G, Butterworth P, Umeda P K, Chang K C. 1991. Strong expression of foreign genes following direct injection into fish muscle. FEBS Letters, 290(1-2): $\quad 73-76, \quad$ https://doi.org/10.1016/00145793(91)81229-2.

Hou W R, Xie S N, Wang H J, Su Y Y, Lu J L, Li L L, Zhang S S, Xiang M. 2011. Intramuscular delivery of a naked DNA plasmid encoding proinsulin and pancreatic regenerating III protein ameliorates type 1 diabetes mellitus. Pharmacological Research, 63(4): 320-327, https://doi.org/10.1016/j.phrs.2010.12.009.

Jung M H, Nikapitiya C, Jung S J. 2018. DNA vaccine encoding myristoylated membrane protein (MMP) of rock bream iridovirus (RBIV) induces protective immunity in rock bream (Oplegnathus fasciatus). Vaccine, 36(6): 802-810, https://doi.org/10.1016/j.vaccine.2017. 12.077 .

Kamei M, Matsuo K, Imanishi H, Hara Y, Quen Y S, Kamiyama F, Oiso N, Kawada A, Okada N, Nakayama T. 2020. 
Transcutaneous immunization with a highly active form of XCL1 as a vaccine adjuvant using a hydrophilic gel patch elicits long-term $\mathrm{CD} 8^{+} \mathrm{T}$ cell responses. Journal of Pharmacological Sciences, 143(3): 182-187, https:/doi. org/10.1016/j.jphs.2020.04.004.

Katou F, Ohtani H, Nakayama T, Nagura H, Yoshie O, Motegi K. 2003. Differential expression of CCL19 by DC-Lamp ${ }^{+}$ mature dendritic cells in human lymph node versus chronically inflamed skin. The Journal of Pathology: A Journal of the Pathological Society Understanding Disease, 199(1): 98-106, https://doi.org/10.1002/path.1255.

Kim J J, Yang J S, Dentchev T, Dang K, Weiner D B. 2000. Chemokine gene adjuvants can modulate immune responses induced by DNA vaccines. Journal of Interferon \& Cytokine Research, 20(5): 487-498, https://doi. org/10.1089/10799900050023906.

Klinman D M, Klaschik S, Tross D, Shirota H, Steinhagen F. 2010. FDA guidance on prophylactic DNA vaccines: analysis and recommendations. Vaccine, 28(16): 28012805, https://doi.org/10.1016/j.vaccine.2009.11.025.

Kono T, Korenaga H. 2013. Th cytokine gene expression in Fugu $\mathrm{T}$ cell subpopulation sorted by specific antibody against CD4. Fish \& Shellfish Immunology, 34(6): 17141715, https://doi.org/10.1016/j.fsi.2013.03.239.

Kono T, Kusuda R, Kawahara E, Sakai M. 2003. The analysis of immune responses of a novel CC-chemokine gene from Japanese flounder Paralichthys olivaceus. Vaccine, 21(56): 446-457, https://doi.org/10.1016/S0264410X(02)00479-6.

Kumar S R, Parameswaran V, Ahmed V P I, Musthaq S S, Hameed A S S. 2007. Protective efficiency of DNA vaccination in Asian seabass (Lates calcarifer) against Vibrio anguillarum. Fish \& Shellfish Immunology, 23(2): 316-326, https://doi.org/10.1016/j.fsi.2006.11.005.

Kutzler M A, Kraynyak K A, Nagle S J, Parkinson R M, Zharikova D, Chattergoon M, Maguire H, Muthumani K, Ugen K, Weiner D B. 2010. Plasmids encoding the mucosal chemokines CCL27 and CCL28 are effective adjuvants in eliciting antigen-specific immunity in vivo. Gene Therapy, 17(1): 72-82, https://doi.org/10.1038/ gt.2009.112.

Kutzler M A, Weiner D B. 2004. Developing DNA vaccines that call to dendritic cells. The Journal of Clinical Investigation, 114(9): 1241-1244, https://doi.org/10.1172/ JCI23467.

Lee J, Kumar S A, Jhan Y Y, Bishop C J. 2018. Engineering DNA vaccines against infectious diseases. Acta Biomaterialia, 80: 31-47, https://doi.org/10.1016/j.actbio. 2018.08.033.

Li C C, Ye Z C, Wen L Y, Chen R, Tian L H, Zhao F K, Pan J Y. 2014. Identification of a novel vaccine candidate by immunogenic screening of Vibrio parahaemolyticus outer membrane proteins. Vaccine, 32(46): 6115-6121, https:// doi.org/10.1016/j.vaccine.2014.08.077.

Li J, Tang L, Li S F, Li G Y, Mo Z L. 2020. The efficacy and side-effects of oil-based adjuvants emulsified Vibrio anguillarum bivalent inactivated vaccine in turbot
(Scophthalmus maximus) under production mode. Aquaculture, 524: 735259, https://doi.org/10.1016/j. aquaculture.2020.735259.

Li Q, Zhan W B, Xing J, Sheng X Z. 2007. Production, characterisation and applicability of monoclonal antibodies to immunoglobulin of Japanese flounder (Paralichthys olivaceus). Fish \& Shellfish Immunology, 23(5): 982-990, https://doi.org/10.1016/j.fsi.2007.03.008.

Li Y X, Sun J S, Sun L. 2011. An inflammatory CC chemokine of Cynoglossus semilaevis is involved in immune defense against bacterial infection. Fish \& Shellfish Immunology, 31(3): 446-452, https://doi.org/10.1016/j.fsi.2011.06.017.

Liu F G, Tang X Q, Sheng X Z, Xing J, Zhan W B. 2016 a. Edwardsiella tarda outer membrane protein $\mathrm{C}$ : an immunogenic protein induces highly protective effects in flounder (Paralichthys olivaceus) against edwardsiellosis. International Journal of Molecular Sciences, 17(7): 1117, https://doi.org/10.3390/ijms17071117.

Liu F G, Tang X Q, Sheng X Z, Xing J, Zhan W B. 2016 b. DNA vaccine encoding molecular chaperone GroEL of Edwardsiella tarda confers protective efficacy against edwardsiellosis. Molecular Immunology, 79: 55-65, https://doi.org/10.1016/j.molimm.2016.09.024.

Liu F G, Tang X Q, Sheng X Z, Xing J, Zhan W B. 2017a. Construction and evaluation of an Edwardsiella tarda DNA vaccine encoding outer membrane protein C. Microbial Pathogenesis, 104: 238-247, https://doi. org/10.1016/j.micpath.2017.01.051.

Liu F G, Tang X Q, Sheng X Z, Xing J, Zhan W B. 2017b. Comparative study of the vaccine potential of six outer membrane proteins of Edwardsiella tarda and the immune responses of flounder (Paralichthys olivaceus) after vaccination. Veterinary Immunology and Immunopathology, 185: 38-47, https://doi.org/10.1016/j. vetimm.2017.01.008.

Livak K J, Schmittgen T D. 2001. Analysis of relative gene expression data using real-time quantitative PCR and the

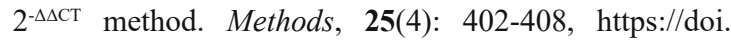
org/10.1006/meth.2001.1262.

Lu S, Wang S X, Grimes-Serrano J M. 2008. Current progress of DNA vaccine studies in humans. Expert Review of Vaccines, 7(2): 175-191, https://doi.org/10.1586/ 14760584.7.2.175.

Matsuo K, Kitahata K, Kawabata F, Kamei M, Hara Y, Takamura S, Oiso N, Kawada A, Yoshie O, Nakayama T. 2018. A highly active form of XCL1/lymphotactin functions as an effective adjuvant to recruit crosspresenting dendritic cells for induction of effector and memory $\mathrm{CD}^{+} \mathrm{T}$ cells. Frontiers in Immunology, 9: 2775, https://doi.org/10.3389/fimmu.2018.02775.

Maurer M, von Stebut E. 2004. Macrophage inflammatory protein-1. The International Journal of Biochemistry \& Cell Biology, 36(10): 1882-1886, https://doi.org/10.1016/j. biocel.2003.10.019.

Moser B, Wolf M, Walz A, Loetscher P. 2004. Chemokines: multiple levels of leukocyte migration control. Trends in Immunology, 25(2): 75-84, https://doi.org/10.1016/j. 
it.2003.12.005.

Nguyen-Hoai T, Hohn O, Vu M D, Baldenhofer G, Ahmed M S S, Dörken B, Norley S, Lipp M, Pezzutto A, Westermann J. 2012. CCL19 as an adjuvant for intradermal gene gun immunization in a Her2/neu mouse tumor model: improved vaccine efficacy and a role for B cells as APC. Cancer Gene Therapy, 19(12): 880-887, https://doi. org/10.1038/cgt.2012.78.

Pinto A R, Reyes-Sandoval A, Ertl H C J. 2003. Chemokines and TRANCE as genetic adjuvants for a DNA vaccine to rabies virus. Cellular Immunology, 224(2): 106-113, https://doi.org/10.1016/j.cellimm.2003.08.006.

Radstake T R D J, van der Voort R, ten Brummelhuis M, de Waal Malefijt M, Looman M, Figdor C G, van den Berg W B, Barrera P, Adema G J. 2005. Increased expression of CCL18, CCL19, and CCL17 by dendritic cells from patients with rheumatoid arthritis, and regulation by $\mathrm{Fc}$ gamma receptors. Annals of the Rheumatic Diseases, 64(3): 359-367, https://doi.org/10.1136/ard.2003.017566.

Romano M, Roupie V, Hamard M, Huygen K. 2006. Evaluation of the immunogenicity of pBudCE4.1 plasmids encoding mycolyl-transferase Ag85A and phosphate transport receptor PstS-3 from Mycobacterium tuberculosis. Vaccine, 24(21): 4640-4643, https://doi.org/10.1016/j. vaccine.2005.08.035.

Somamoto T, Kondo M, Nakanishi T, Nakao M. 2014. Helper function of $\mathrm{CD}^{+}$lymphocytes in antiviral immunity in ginbuna crucian carp, Carassius auratus langsdorfii. Developmental \& Comparative Immunology, 44(1): 111115, https://doi.org/10.1016/j.dci.2013.12.008.

Stewart T J, Smyth M J, 2008. Chemokine-chemokine receptors in cancer immunotherapy. Immunotherapy, 1(1): 109-127, https://doi.org/10.2217/1750743X.1.1.109.

Su B W, Wang J P, Wang X, Jin H L, Zhao G, Kang Y M, Wang B. 2008. The effects of IL- 6 and TNF- $\alpha$ as molecular adjuvants on immune responses to FMDV and maturation of dendritic cells by DNA vaccination. Vaccine, 26(40): 5111-5122, https://doi.org/10.1016/j.vaccine.2008.03.089.

Takizawa F, Magadan S, Parra D, Xu Z, Korytáŕ T, Boudinot P, Sunyer J O. 2016. Surface expression of trout CD4-1 and CD4-2 defines novel populations of functionally distinct CD4+ T cells in teleost fish. Fish \& Shellfish Immunology, 53: 88, https://doi.org/10.1016/j.fsi.2016. 03.131.

Tang X Q, Guo M, Sheng X Z, Xing J, Zhan W B. 2020. Interleukin-2 (IL-2) of flounder (Paralichthys olivaceus) as immune adjuvant enhance the immune effects of $E$. tarda subunit vaccine OmpV against Edwardsiellosis. Developmental \& Comparative Immunology, 106: 103615, https://doi.org/10.1016/j.dci.2020.103615.

Tang X Q, Zhou L, Zhan W B. 2008. Isolation and characterization of pathogenic Listonella anguillarum of diseased half-smooth tongue sole (Cynoglossus semilaevis Günther). Journal of Ocean University of China, 7(3): 343-351, https://doi.org/10.1007/s11802-008-0343-3.

Tian H F, Xing J, Tang X Q, Sheng X Z, Zhan W B. 2019. Characterization of flounder (Paralichthys olivaceus)
CD4+ $\mathrm{T}$ lymphocyte subsets in response to Th-type antigens. Fish \& Shellfish Immunology, 91: 464, https:// doi.org/10.1016/j.fsi.2019.04.270.

Tovey M G, Lallemand C. 2010. Adjuvant activity of cytokines. Methods in Molecular Biology, 626: 287-309, https://doi. org/10.1007/978-1-60761-585-9_19.

Vazquez-Juarez R C, Gomez-Chiarri M, Barrera-Saldaña H, Hernandez-Saavedra N, Dumas S, Ascencio F. 2005. Evaluation of DNA vaccination of spotted sand bass (Paralabrax maculatofasciatus) with two major outermembrane protein-encoding genes from Aeromonas veronii. Fish \& Shellfish Immunology, 19(2): 153-163, https://doi.org/10.1016/j.fsi.2004.12.007.

Wu N, Li C J, Gui J F. 2009. Molecular characterization and functional commonality of nucleophosmin/nucleoplasmin in two cyprinid fish. Biochemical Genetics, 47(11-12): 749, https://doi.org/10.1007/s10528-009-9274-y.

Xing J, Zhou X J, Tang X Q, Sheng X Z, Zhan W B. 2018. FlaC supplemented with VAA, OmpK or OmpR as bivalent subunit vaccine candidates induce immune responses against Vibrio anguillarum in flounder (Paralichthys olivaceus). Vaccine, 36(10): 1316-1322, https://doi.org/10.1016/j.vaccine.2017.11.074.

Xu H S, Xing J, Tang X Q, Sheng X Z, Zhan W B. 2019a. Intramuscular administration of a DNA vaccine encoding OmpK antigen induces humoral and cellular immune responses in flounder (Paralichthys olivaceus) and improves protection against Vibrio anguillarum. Fish \& Shellfish Immunology, 86: 618-626, https://doi. org/10.1016/j.fsi.2018.11.073.

Xu H S, Xing J, Tang X Q, Sheng X Z, Zhan W B. 2019b. Generation and functional evaluation of a DNA vaccine co-expressing Vibrio anguillarum VAA protein and flounder interleukin-2. Fish \& Shellfish Immunology, 93: 1018-1027, https://doi.org/10.1016/j.fsi.2019.08.052.

Xu H S, Xing J, Tang X Q, Sheng X Z, Zhan W B. 2019c. Immune response and protective effect against Vibrio anguillarum induced by DNA vaccine encoding Hsp33 protein. Microbial Pathogenesis, 137: 103729, https://doi. org/10.1016/j.micpath.2019.103729.

Xu H S, Xing J, Tang X Q, Sheng X Z, Zhan W B. 2020. The effects of CCL3, CCL4, CCL19 and CCL21 as molecular adjuvants on the immune response to VAA DNA vaccine in flounder (Paralichthys olivaceus). Developmental \& Comparative Immunology, 103: 103492, https://doi. org/10.1016/j.dci.2019.103492.

Yamano T, Kaneda Y, Huang S, Hiramatsu S H, Hoon D S B. 2006. Enhancement of immunity by a DNA melanoma vaccine against TRP2 with CCL21 as an adjuvant. Molecular Therapy, 13(1): 194-202, https://doi.org/10. 1016/j.ymthe.2005.05.018.

Yan Y H, Yu F, Zeng C, Cao L H, Zhang Z, Xu Q A. 2016. CCL17 combined with CCL19 as a nasal adjuvant enhances the immunogenicity of an anti-caries DNA vaccine in rodents. Acta Pharmacologica Sinica, 37(9): 1229-1236, https://doi.org/10.1038/aps.2016.73.

Yoshida R, Imai T, Hieshima K, Kusuda J, Baba M, Kitaura M, 
Nishimura M, Kakizaki M, Nomiyama H, Yoshie O. 1997. Molecular cloning of a novel human CC chemokine EBI1-ligand chemokine that is a specific functional ligand for EBI1, CCR7. Journal of Biological Chemistry, 272(21): $\quad$ 13803-13809, https://doi.org/10.1074/ jbc.272.21.13803.

Zahm C D, Colluru V T, McNeel D G. 2017. DNA vaccines for prostate cancer. Pharmacology \& Therapeutics, 174: 2742, https://doi.org/10.1016/j.pharmthera.2017.02.016.

Zhang X H, Shi Y H, Chen J. 2015. Molecular characterization of a transmembrane C-type lectin receptor gene from ayu (Plecoglossus altivelis) and its effect on the recognition of different bacteria by monocytes/macrophages. Molecular immunology, 66(2): 439-450, https://doi.org/10.1016/j. molimm.2015.05.009.

Zhu Z M, Dong C F, Weng S P, He J G. 2019. Identification of outer membrane protein $\mathrm{TolC}$ as the major adhesin and potential vaccine candidate for Vibrio harveyi in hybrid grouper, Epinephelus fuscoguttatus $(+) \times$ E. lanceolatus (ठ). Fish \& Shellfish Immunology, 86: 143-151, https:// doi.org/10.1016/j.fsi.2018.11.037.

Zou G G, Nozaki R, Kondo H, Hirono I. 2014. Cloning and expression analysis of three novel CC chemokine genes from Japanese flounder (Paralichthys olivaceus). Fish \& Shellfish Immunology, 40(2): 507-513, https://doi.org/10. 1016/j.fsi.2014.08.003.

\section{Electronic supplementary material}

Supplementary material (Supplementary Material) is available in the online version of this article at https:// doi.org/10.1007/s00343-021-1092-z. 